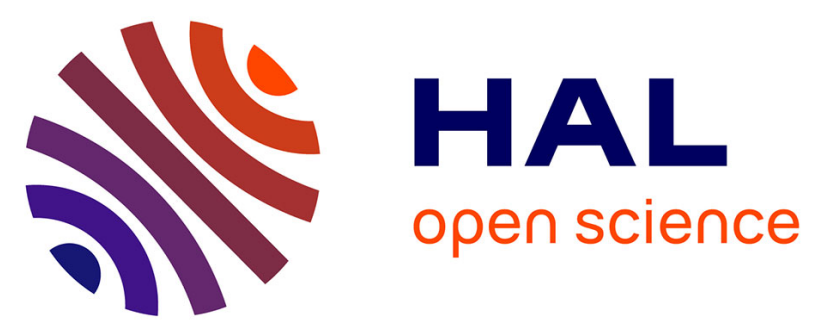

\title{
Imaging of Dysfunctional Elastogenesis in Atherosclerosis Using an Improved Gadolinium-Based Tetrameric MRI Probe Targeted to Tropoelastin
}

Federico Capuana, Alkystis Phinikaridou, Rachele Stefania, Sergio Padovan, Begoña Lavin, S. Lacerda, Eyad Almouazen, Yves Chevalier, Laurence Heinrich-Balard, René Botnar, et al.

\section{To cite this version:}

Federico Capuana, Alkystis Phinikaridou, Rachele Stefania, Sergio Padovan, Begoña Lavin, et al.. Imaging of Dysfunctional Elastogenesis in Atherosclerosis Using an Improved Gadolinium-Based Tetrameric MRI Probe Targeted to Tropoelastin. Journal of Medicinal Chemistry, 2021, 64 (20), pp.15250-15261. 10.1021/acs.jmedchem.1c01286 . hal-03433450

\author{
HAL Id: hal-03433450 \\ https://hal.science/hal-03433450
}

Submitted on 18 Nov 2021

HAL is a multi-disciplinary open access archive for the deposit and dissemination of scientific research documents, whether they are published or not. The documents may come from teaching and research institutions in France or abroad, or from public or private research centers.
L'archive ouverte pluridisciplinaire HAL, est destinée au dépôt et à la diffusion de documents scientifiques de niveau recherche, publiés ou non, émanant des établissements d'enseignement et de recherche français ou étrangers, des laboratoires publics ou privés. 


\section{Imaging of Dysfunctional Elastogenesis in Atherosclerosis Using an Improved Gadolinium-Based Tetrameric MRI Probe Targeted to Tropoelastin}

Federico Capuana, ${ }^{\S}$ Alkystis Phinikaridou, ${ }^{\S}$ Rachele Stefania, Sergio Padovan, Begoña Lavin, Sara Lacerda, Eyad Almouazen, Yves Chevalier, Laurence Heinrich-Balard, René M. Botnar, Silvio Aime, and Giuseppe Digilio*

Cite This: J. Med. Chem. 2021, 64, 15250-15261

Read Online

ACCESS I

Llll Metrics \& More

Article Recommendations

Supporting Information

ABSTRACT: Dysfunctional elastin turnover plays a major role in the progression of atherosclerotic plaques. Failure of tropoelastin cross-linking into mature elastin leads to the accumulation of tropoelastin within the growing plaque, increasing its instability. Here we present $\mathrm{Gd}_{4}$-TESMA, an MRI contrast agent specifically designed for molecular imaging of tropoelastin within plaques. $\mathrm{Gd}_{4}$-TESMA is a tetrameric probe composed of a tropoelastin-binding peptide (the VVGS-peptide) conjugated with four Gd(III)-DOTA-monoamide chelates. It shows a relaxivity per molecule of $34.0 \pm 0.8 \mathrm{mM}^{-1} \mathrm{~s}^{-1}(20 \mathrm{MHz}, 298 \mathrm{~K}, \mathrm{pH} 7.2)$, a good binding affinity to tropoelastin $\left(K_{\mathrm{D}}=41 \pm 12 \mu \mathrm{M}\right)$, and a serum half-life longer than $2 \mathrm{~h}$. $\mathrm{Gd}_{4}$-TESMA accumulates specifically in atherosclerotic plaques in the $\mathrm{ApoE}^{-/-}$

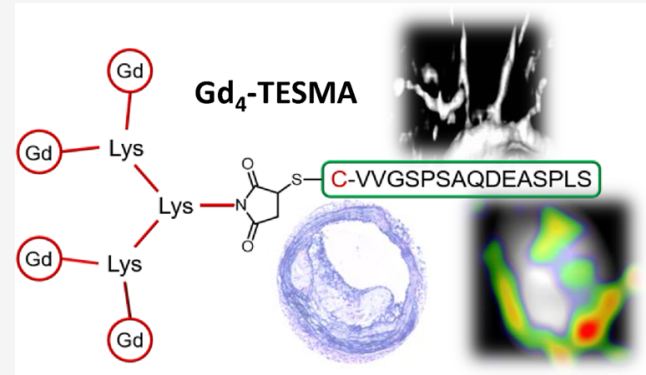
murine model of plaque progression, with $2 \mathrm{~h}$ persistence of contrast enhancement. As compared to the monomeric counterpart (Gd-TESMA), the tetrameric $\mathrm{Gd}_{4}$-TESMA probe shows a clear advantage regarding both sensitivity and imaging time window, allowing for a better characterization of atherosclerotic plaques.

\section{INTRODUCTION}

Atherosclerotic plaque rupture is one of the leading causes of life-threatening cardiovascular events. The size of atherosclerotic plaques and the extent of luminal stenosis can be assessed by several imaging techniques, but these morphological parameters alone are not reliable diagnostic indicators of the risk for plaque rupture. ${ }^{1}$ Depending on the morphology, composition, and histopathologic features, plaques have been classified as stable or high risk (vulnerable/unstable). Pathology studies revealed that plaques at high risk of rupturing with ensuing thrombosis are characterized by a thin fibrous cap, a large necrotic lipid-rich core, microcalcifications, and increased macrophage infiltration. ${ }^{2}$ Increased plaque microvessel density may lead to intraplaque hemorrhage, further increasing the risk of rupture. ${ }^{3}$ Phenotyping of atherosclerotic plaques by noninvasive imaging techniques has emerged as an essential requirement for risk assessment. ${ }^{4}$ Vulnerable-plaque imaging aims at detecting biomarkers that would allow classifying plaques according to their risk of rupture.

Elastin is a major component of the arterial wall matrix. Dysfunctional elastin turnover promotes atherosclerotic plaque progression. ${ }^{5-10}$ This turnover involves a balance between elastolysis - the degradation of fibers and elastogenesis-de novo synthesis, and cross-linking of the newly synthesized soluble tropoelastin (TE) precursor into mature polymeric elastin. ${ }^{11}$ In atherosclerosis, elastolysis is enhanced by inflammation-driven upregulation of elastases. ${ }^{12}$ Simultaneously, elastin synthesis resumes and new tropoelastin molecules are produced by plaque macrophages and vascular smooth muscle cells. ${ }^{5}$ However, tropoelastin monomers frequently fail to cross-link into mature polymeric elastin as a result of the reduced expression or absence of lysyl oxidase $(\mathrm{LOX})^{13-15}$ or any of the components of the microfibrillar scaffold required for fiber assembly. ${ }^{16-19}$ Therefore, tropoelastin accumulates within the growing lesion, promoting plaque progression and instability. ${ }^{9}$

Imaging probes targeting plaque elastin and tropoelastin have been developed to enable the quantitative assessment of elastin turnover and the phenotyping of plaques and to assess their potential for rupture. Most of the studies in preclinical models of atherosclerosis ${ }^{10,20,21}$ and other vascular diseases $^{22-25}$ focused on total elastin imaging by using a low molar mass probe (Gd-ESMA). ${ }^{24,26}$ This elastin-specific MR agent binds to both mature/cross-linked and monomeric

Received: July 20, 2021

Published: October 18, 2021 


\section{Scheme 1. Chemical Structures of Gd-TESMA and Gd $\mathrm{d}_{4}$-TESMA}
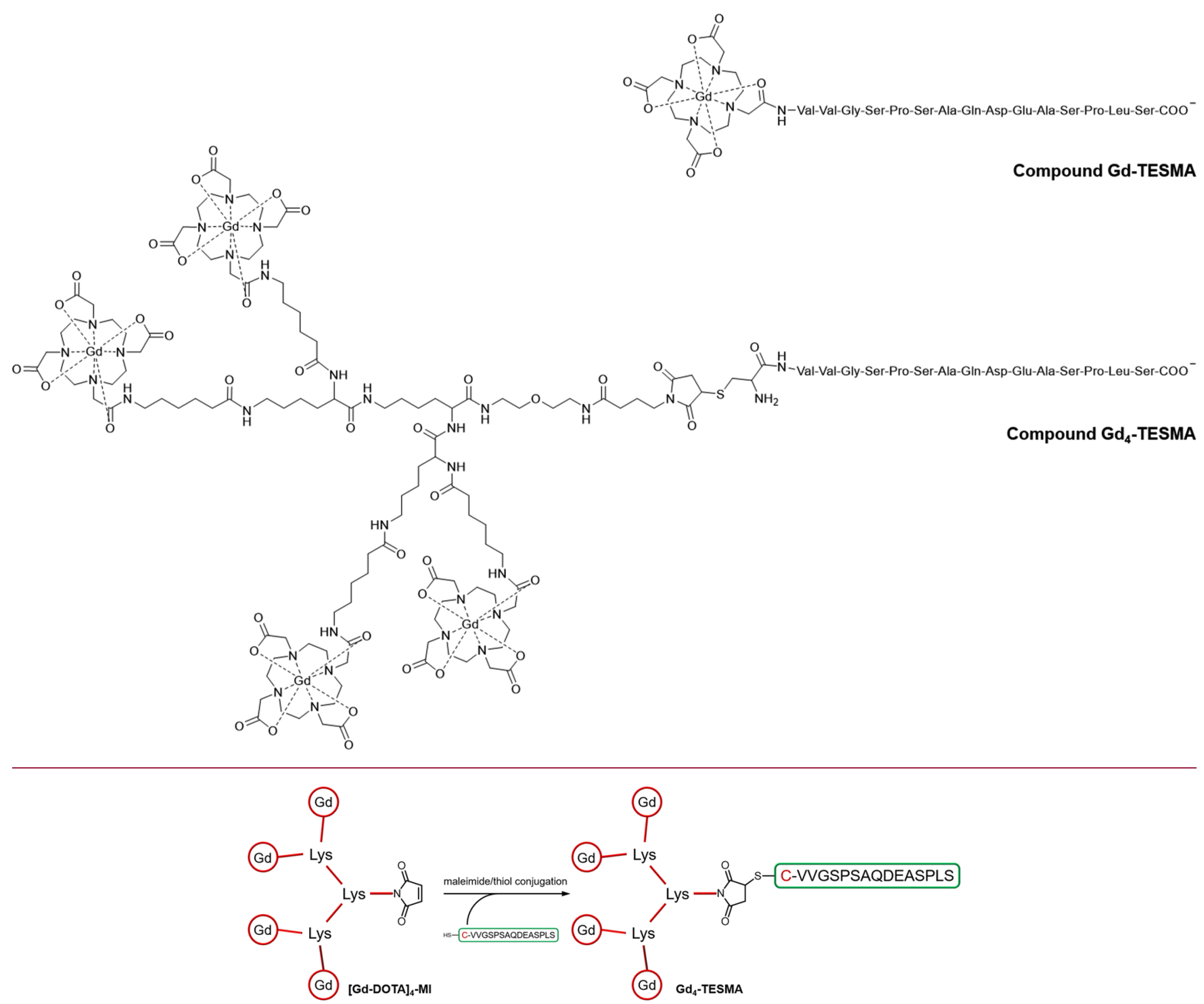

Figure 1. Synthetic approach to $\mathrm{Gd}_{4}$-TESMA.

tropoelastin molecules. More recently, a new probe designed to specifically bind to monomeric tropoelastin has been used for plaque phenotyping. ${ }^{9,27}$ This molecular probe, called GdTESMA (Scheme 1), consists of a single Gd-DOTA monoamide unit (DOTA $=1,4,7,10$-tetraazacyclododecane1,4,7,10-tetraacetic acid) conjugated with a 15 -residue peptide sequence (named VVGS-peptide) that showed a good binding affinity for tropoelastin and good selectivity over elastin and a panel of other matrix proteins.

Studies in an apolipoprotein-E-deficient $\left(\mathrm{ApoE}^{-/-}\right)$murine model of progressive atherosclerosis and abdominal aortic aneurysm showed improved visualization of vessel walls during disease progression that correlated with the levels of tropoelastin as detected by ex vivo histology and Western blotting. Interestingly, studies in a rabbit model of plaque rupture showed higher tropoelastin content and Gd-induced relaxation rates in rupture-prone compared with stable plaques. Therefore, tropoelastin is a novel MRI biomarker for atherosclerotic plaque progression and instability, and aortic aneurysm expansion. 9,27
Here, we report a new and improved version of the tropoelastin-specific MRI probe aimed at improving the pharmacokinetics, increasing the sensitivity for MRI detection, and extending the duration of the imaging window. To achieve that, we linked four Gd-chelates to the same tropoelastin recognizing peptide moiety to accumulate multiple copies of the gadolinium moiety within a single binding event. A lysinebased tetramer containing four Gd-DOTA monoamide chelates was conjugated to the tropoelastin-binding VVGSpeptide to obtain the compound $\mathrm{Gd}_{4}$-TESMA by adapting a synthetic approach previously described (Figure 1). ${ }^{28,2}$

The tetrameric imaging reporter was designed as a flexible molecule for minimizing binding interference to the biological target. Moreover, increasing the molecular size of the imaging probe could improve pharmacokinetics in plaques, potentially allowing for a longer imaging time window. Interestingly, the increased density of gadolinium at the biological target may pave the way for imaging atherosclerosis using techniques other than MRI, such as the novel spectral photon counting computed tomography (SPCCT). This is an X-ray technique 


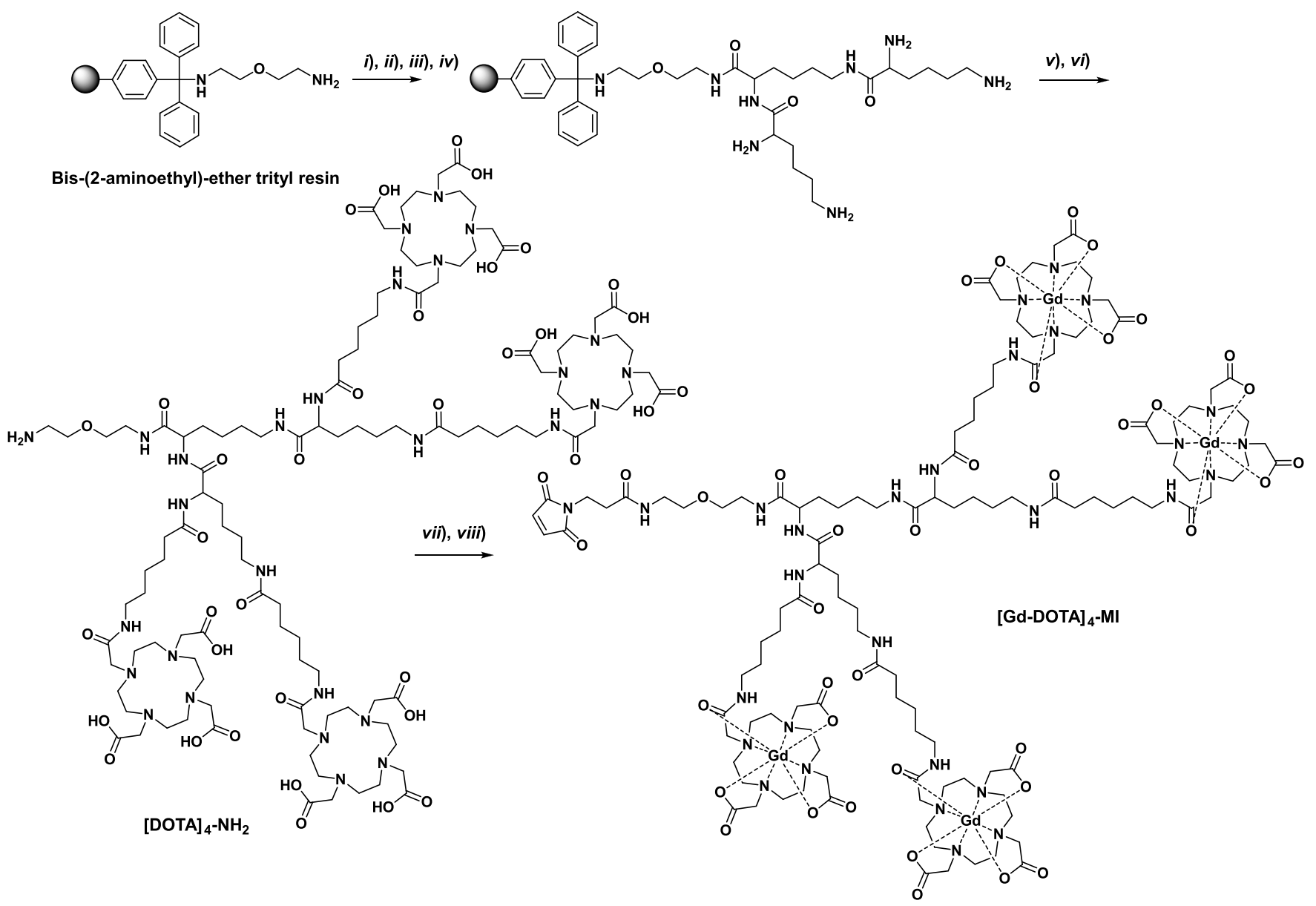

Figure 2. Synthesis of [Gd-DOTA $]_{4}$-MI. (i) Fmoc-Lys(Fmoc)-OH, PyBOP, DIPEA, DMF, 1 h, 20\% acetic anhydride; (ii) 40\% piperidine-DMF (5 $\mathrm{min}$ ) and 20\% piperidine-DMF (15 min); (iii) Fmoc-Lys(Fmoc)-OH, PyBOP, DIPEA, DMF,1 h; (iv) 40\% piperidine-DMF (5 min) and 20\% piperidine-DMF (15 min); $(v)$ DOTA $(t \mathrm{Bu})_{3} \mathrm{CONH}\left(\mathrm{CH}_{2}\right)_{5} \mathrm{COOH}$, PyBOP, DIPEA, DMF, $2 \mathrm{~h}$; (vi) TFA, DCM, TIS 49:49:2 (20 min) and TFA $100 \%$ (12 h); (vii) $\mathrm{GdCl}_{3}$ in water; and (viii) $\mathrm{N}$-succinimidyl-3-maleimidopropionate in $50 \mathrm{mM}$ phosphate buffer.

that can be tailored to the selective detection of gadolinium by its K-edge specific absorption. ${ }^{30-32}$

\section{RESULTS}

Synthesis and Characterization of $\mathrm{Gd}_{4}$-TESMA. The general synthetic approach to $\mathrm{Gd}_{4}$-TESMA relied on the synthesis of a tetrameric Gd-DOTA-like chelate functionalized with a maleimide function (compound [Gd-DOTA $]_{4}-\mathrm{MI}$ ). This gadolinium tetramer was then conjugated to a cysteine residue added at the $\mathrm{N}$-terminus of the tropoelastin specific binding sequence (C-VVGSPSAQDEASPLS) through the thiol/maleimide reaction to yield the final $\mathrm{Gd}_{4}$-TESMA imaging probe (Figure 1).

The tetrameric chelator based on DOTA (compound $\left.[\text { DOTA }]_{4}-\mathrm{NH}_{2}\right)$ was synthesized by a solid phase peptide synthesis (SPPS) approach. This approach relies on $(i)$ the attachment of the first lysine to a solid polymer by a covalent bond, (ii) the addition of two more lysines followed by the four DOTA-based chelating cages, and (iii) the final removal of the compound from the solid support (Figure 2).

The bis(2-aminoethyl)ether trityl resin and 9-fluorenylmethyloxycarbonyl (Fmoc) protection chemistry were chosen for the setup of the synthesis. After coupling the first lysine residue (under the form of $\mathrm{N} \alpha, \mathrm{N} \varepsilon$-di-Fmoc-L-lysine) to the resin, the resin was treated with acetic anhydride in DMF to acetylate the residual free amino groups exposed on its surface. After the removal of Fmoc by the addition of piperidine in DMF, two more lysine residues were attached. The coupling reactions were performed with 2.5-fold excess Fmoc-Lys(Fmoc)-OH in DMF, with PyBOP as the activator and DIPEA as the base. The branched tri-lysine core anchored on the resin provided four amino groups (two $\alpha$-amino and two side-chain $\varepsilon$-amino groups) for attachment of the DOTA-like chelators. The latter coupling was performed with a small excess of the DOTA derivative $\operatorname{DOTA}(t \mathrm{Bu})_{3} \mathrm{CONH}\left(\mathrm{CH}_{2}\right)_{5} \mathrm{COOH}$, whose synthesis has been described previously. ${ }^{33}$ The coupling reaction between DOTA and the tri-lysine scaffold turned out to be a tricky step, as the final yield was strongly dependent upon the activating agent. PyBOP as the activator was clearly superior to HBTU. The latter activator showed decreased yields because of the transfer of a tetramethyluronium moiety from HBTU to a lysine amino group, with the formation of a stable tetramethylguanidine derivative. ${ }^{29,34}$ Cleavage from the resin and purification by semipreparative HPLC afforded [DOTA $]_{4}$ $\mathrm{NH}_{2}$ with an overall yield of about $60 \%$ and purity of $98 \%(\lambda=$ $220 \mathrm{~nm}$ ). The Gd(III)-complex (compound [Gd-DOTA $]_{4^{-}}$ $\mathrm{NH}_{2}$ ) was prepared by mixing stoichiometric amounts of [DOTA $]_{4}-\mathrm{NH}_{2}$ and $\mathrm{GdCl}_{3}$ solution (1:4 ratio). After complexation, the amine end-group of the molecular structure of [GdDOTA $]_{4}-\mathrm{NH}_{2}$ was easily converted into maleimide (compound $\left.[\mathrm{Gd}-\mathrm{DOTA}]_{4}-\mathrm{MI}\right)$ by reacting the tetrameric compound with a 3-fold molar excess of $\mathrm{N}$-succinimidyl-3- 
maleimido propionate in phosphate buffer $50 \mathrm{mM}$ and acetonitrile (3:1 ratio). Since some loss of the functionalized compound may take place because of the hydrolysis of the maleimide group in the aqueous solution, we optimized the reaction to condition such to have total conversion within $1 \mathrm{~h}$ by carefully maintaining $\mathrm{pH}$ at 6.5. UPLC-UV-MS (ESI+) analysis after the removal of excess reagents and salts by size exclusion chromatography showed a purity $>88 \%(\lambda=220$ $\mathrm{nm})$.

The tropoelastin binding sequence, ending up with a cysteine residue at the $\mathrm{N}$-terminus, was synthesized by standard SPPS by means of the Fmoc chemistry with 2chlorotrityl chloride resin. The fully deprotected peptide was purified by semipreparative HPLC (98\% purity) and then was reacted with $[\mathrm{Gd}-\mathrm{DOTA}]_{4} \mathrm{MI}$ at a molar ratio of $1: 1$ at $\mathrm{pH} 6.5$ to yield the final product $\mathrm{Gd}_{4}$-TESMA. After a final purification step by semipreparative HPLC, an overall yield of about $60 \%$ and purity $>95 \%(\lambda=220 \mathrm{~nm})$ were achieved. It is worth emphasizing that, by such a procedure, a purified, preformed tetrameric $\mathrm{Gd}(\mathrm{III})$-chelate is directly conjugated to the targeting vector. This approach eliminates the potential issue of "free" gadolinium, i.e., the presence of Gd(III) ions being weakly coordinated to secondary coordinating sites potentially available in the peptide structure.

Relaxivity Studies. The relaxivity per gadolinium of $\mathrm{Gd}_{4}$ TESMA is $8.5 \pm 0.2 \mathrm{mM}^{-1} \mathrm{~s}^{-1}$ (at $20 \mathrm{MHz}, 298 \mathrm{~K}, 3.8 \mathrm{mM}$ HEPES, $150 \mathrm{mM} \mathrm{NaCl}, \mathrm{pH}$ 7.2; Table 1), while that of Gd-

Table 1. Relaxivities of $\mathrm{Gd}_{4}$-TESMA and Gd-TESMA at 20 and $125 \mathrm{MHz}$ (298 K, $3.8 \mathrm{mM}$ HEPES, $150 \mathrm{mM} \mathrm{NaCl}, \mathrm{pH}$ 7.2)

\begin{tabular}{|c|c|c|}
\hline compound & $\begin{array}{c}r_{1}^{\mathrm{mM}}\left(\mathrm{mM}^{-1} \mathrm{~s}^{-1}\right) \text { at } 20 \\
\mathrm{MHz}\end{array}$ & $\begin{array}{c}r_{1}^{\mathrm{mM}}\left(\mathrm{mM}^{-1} \mathrm{~s}^{-1}\right) \text { at } 125 \\
\mathrm{MHz}\end{array}$ \\
\hline \multicolumn{3}{|l|}{$\mathrm{Gd}_{4}$-TESMA } \\
\hline per molecule & $34.0 \pm 0.8$ & $32.4 \pm 0.8$ \\
\hline per Gd(III) & $8.5 \pm 0.2$ & $8.1 \pm 0.2$ \\
\hline $\begin{array}{c}\text { Gd-TESMA } \\
(1 \mathrm{mM})\end{array}$ & $10.0 \pm 0.3$ & $10.4 \pm 0.3$ \\
\hline
\end{tabular}

TESMA under the same conditions cannot be defined uniquely as it changes with the concentration of the complex. Namely, it increases from $6.1 \mathrm{mM}^{-1} \mathrm{~s}^{-1}$ at $18 \mu \mathrm{M}$ to $12.4 \mathrm{mM}^{-1} \mathrm{~s}^{-1}$ at 2.3 $\mathrm{mM}$ (Figure 3).

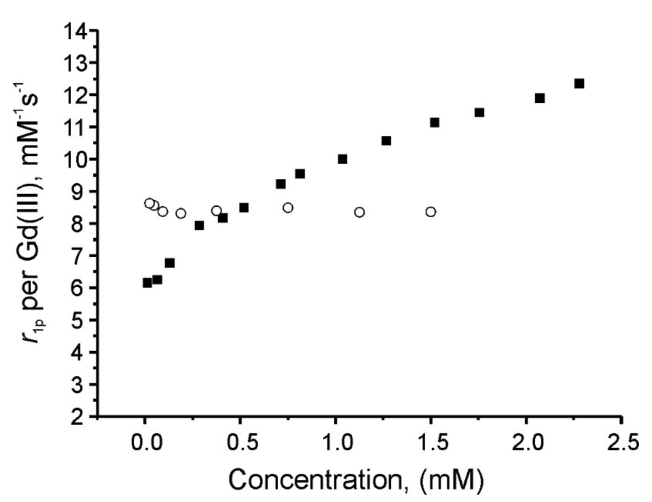

Figure 3. Plot of the millimolar relaxivity per gadolinium $r_{1 \mathrm{p}}$ of GdTESMA (solid squares) and $\mathrm{Gd}_{4}$-TESMA (open circles) as a function of the probe concentration $(20 \mathrm{MHz}, 298 \mathrm{~K}, 3.8 \mathrm{mM}$ HEPES, 150 $\mathrm{mM} \mathrm{NaCl}, \mathrm{pH}$ 7.2).
Such behavior can be explained by the formation of polydispersed aggregates, whose average size and size distribution progressively increase with the concentration. It is worth noting that a similar dependence of the relaxivity with the concentration was observed for other peptidic probes having a closely related structure. ${ }^{35}$ The ${ }^{1} \mathrm{H}$ nuclear magnetic resonance dispersion (NMRD) profiles of $\mathrm{Gd}_{4}$-TESMA and Gd-TESMA were acquired to get more insights into the factors driving their relaxivity (Figure 4).

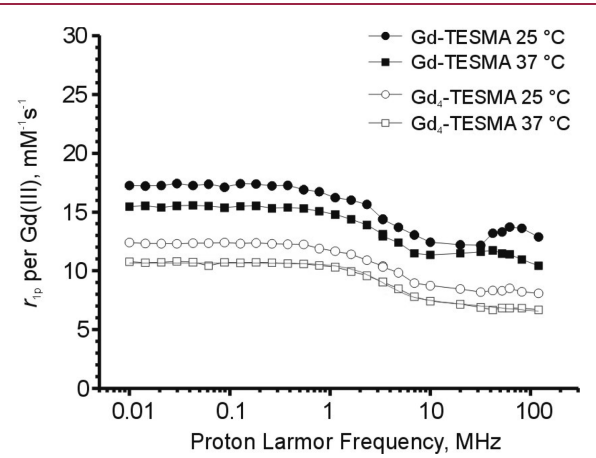

Figure 4. ${ }^{1} \mathrm{H}$ NMRD profiles showing the millimolar relaxivity per gadolinium $r_{1 \mathrm{p}}$ of Gd-TESMA (2.3 $\mathrm{mM}$, solid symbols) and $\mathrm{Gd}_{4^{-}}$ TESMA (1.3 mM, open symbols) in the HEPES buffer $(\mathrm{pH} 7.2)$ at $298 \mathrm{~K}$ (circles) and $310 \mathrm{~K}$ (squares). The solid line represents the best fitting of the experimental points at $310 \mathrm{~K}$ to the SBM and Freed theory of paramagnetic relaxation. The following parameters were kept fixed: water diffusion coefficient $(D)=3.110^{-5} \mathrm{~cm}^{2} \mathrm{~s}^{-1}$; distance between $\mathrm{Gd}(\mathrm{III})$ and the inner sphere water protons $(r)=3.1 \AA$; number of inner sphere water molecules $(q)=1$; and distance of the closest approach of outer-sphere water protons $=3.8 \AA$. Curve fitting converged to the following: correlation time for molecular reorientation $\left(\tau_{\mathrm{R}}\right)=170 \mathrm{ps}$; residence lifetime of the inner sphere water molecule $\left(\tau_{\mathrm{M}}\right)=460 \mathrm{~ns}$; correlation time for electronic relaxation $\left(\tau_{\mathrm{v}}\right)=47 \mathrm{ps}$; and zero-field splitting energy $\left(\Delta^{2}\right)=1.310^{19}$ $\mathrm{s}^{-2}$.

Despite its molar mass of about $4.8 \mathrm{kDa}$, the ${ }^{1} \mathrm{H}$ NMRD profile of $\mathrm{Gd}_{4}$-TESMA shows a monotonic single dispersion that is typical of low molar mass Gd-DOTA monoamide compounds characterized by fast molecular tumbling motions. ${ }^{36}$ Multiparametric fitting of the ${ }^{1} \mathrm{H}$ NMRD profile at 310 $\mathrm{K}$ yielded an estimate of the molecular correlation time for molecular tumbling $\left(\tau_{\mathrm{R}}\right)$ of $170 \mathrm{ps}$ according to the SolomonBloembergen-Morgan (SBM) theory for inner sphere paramagnetic relaxation combined with the Freed theory for the outer sphere contribution. ${ }^{37-39}$ This value is between that of a true low molar mass Gd-DOTA monoamide complex (about $80 \mathrm{ps})^{36}$ and that expected for a rigid system with $5 \mathrm{kDa}$ molar mass (of the order of nanoseconds) ${ }^{37}$ and comparable to that of other multimeric Gd-DOTA monoamide based compounds $(240 \mathrm{ps}){ }^{40}$ This can be ascribed to the high flexibility of the linkers connecting the paramagnetic centers to the peptide moiety, which decouples local motions of the $\mathrm{Gd}(\mathrm{III})$ chelating cages from global molecular reorientation motions. ${ }^{28,35,41}$ The ${ }^{1} \mathrm{H}$ NMRD profile of Gd-TESMA (at 2.3 $\mathrm{mM}$ concentration) showed a weak but still appreciable relaxivity peak centered at about $40 \mathrm{MHz}$ corresponding to slow tumbling systems (i.e., systems having a large size). Although such a relaxivity peak was much smaller compared with truly rigid macromolecular systems (e.g., nanosystems), ${ }^{42}$ it confirmed that the system self-assembled into aggregates with high polydispersity at relatively high concentrations. The 

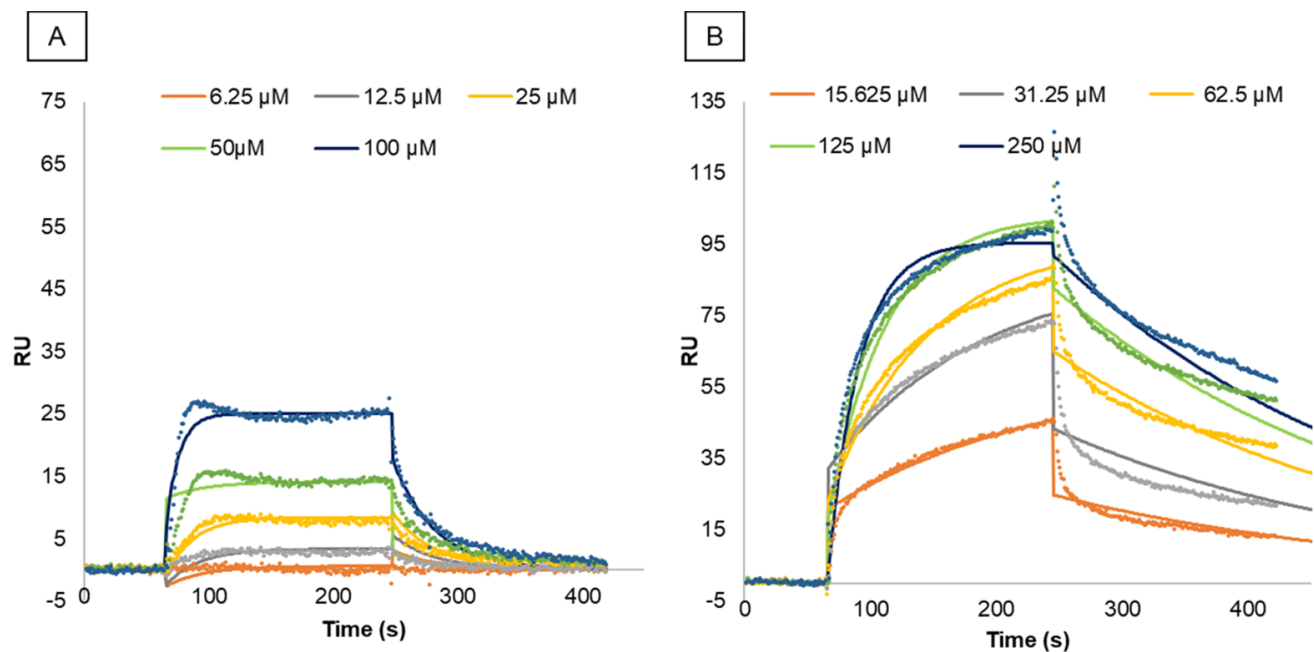

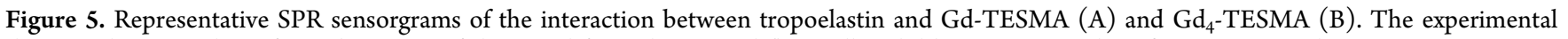
data are shown as dots after subtraction of the signal from the control flow cell. Solid lines represent best-fit curves according to a 1:1 Langmuir binding model.

${ }^{1} \mathrm{H}$ NMRD profile can be thought as arising from the contribution of species spanning from monomers to aggregates having a heterogeneous dispersion of molecular size that cannot be accounted for by our fitting model. As a matter of fact, the standard SBM model did not converge to a meaningful fit of the data.

In Vitro Binding Affinity. The binding affinity of GdTESMA and $\mathrm{Gd}_{4}$-TESMA to tropoelastin was assessed by surface plasmon resonance (SPR) under the kinetic affinity mode. The sensorgrams of Gd-TESMA and $\mathrm{Gd}_{4}$-TESMA at their increasing concentrations indicated a good interaction of both ligands with the immobilized tropoelastin (Figure 5). The fitting of sensorgram data to the 1:1 binding model allowed the estimation of the equilibrium dissociation constant $K_{\mathrm{D}}$ for GdTESMA $(28 \pm 12 \mu \mathrm{M})$ and $\operatorname{Gd}_{4}$-TESMA $(41 \pm 12 \mu \mathrm{M})$, confirming similar binding affinities of the two probes to tropoelastin (Table 2). Higher association $\left(k_{\mathrm{a}}\right)$ and dissocia-

Table 2. Association Rate Constant $k_{\mathrm{a}}$, Dissociation Rate Constant $k_{\mathrm{d}}$, and Equilibrium Dissociation Constant $K_{\mathrm{D}}$ Characterizing the Interaction between Immobilized Human Recombinant Tropoelastin and Gd-TESMA/ Gd $_{4}$ TESMA $^{a}$

$\begin{array}{cccc}\text { analyte } & k_{\mathrm{a}}\left(\mathrm{M}^{-1} \mathrm{~s}^{-1}\right) & k_{\mathrm{d}}\left(\mathrm{s}^{-1}\right) & K_{\mathrm{D}}(\mu \mathrm{M}) \\ \text { Gd-TESMA } & 880 \pm 160 & 2.3 \times 10^{-2} \pm 0.5 \times 10^{-2} & 28 \pm 12 \\ \text { Gd }_{4} \text {-TESMA } & 94 \pm 40 & 3.4 \times 10^{-3} \pm 0.3 \times 10^{-3} & 41 \pm 12\end{array}$

${ }^{a}$ Values are mean \pm SD from triplicate measurements.

tion $\left(k_{\mathrm{d}}\right)$ rate constants were estimated for Gd-TESMA as compared to $\mathrm{Gd}_{4}$-TESMA; this was likely related to the difference of their molar masses.

Serum Stability Assays. The stabilities of $\mathrm{Gd}_{4}$-TESMA and the parent VVGS-peptide in human serum were evaluated by HPLC (Figure 6). Compounds were incubated up to 120 min, and aliquots were taken at different times: 0,35 , and 120 min. The VVGS-peptide showed a half-life in serum of about $45 \mathrm{~min}$. After $2 \mathrm{~h}$, about $20 \%$ of the VVGS-peptide remained in the serum. On the other hand, $\mathrm{Gd}_{4}$-TESMA could be recovered unchanged after $2 \mathrm{~h}$ of incubation. This demonstrates a very good stability in serum both toward the

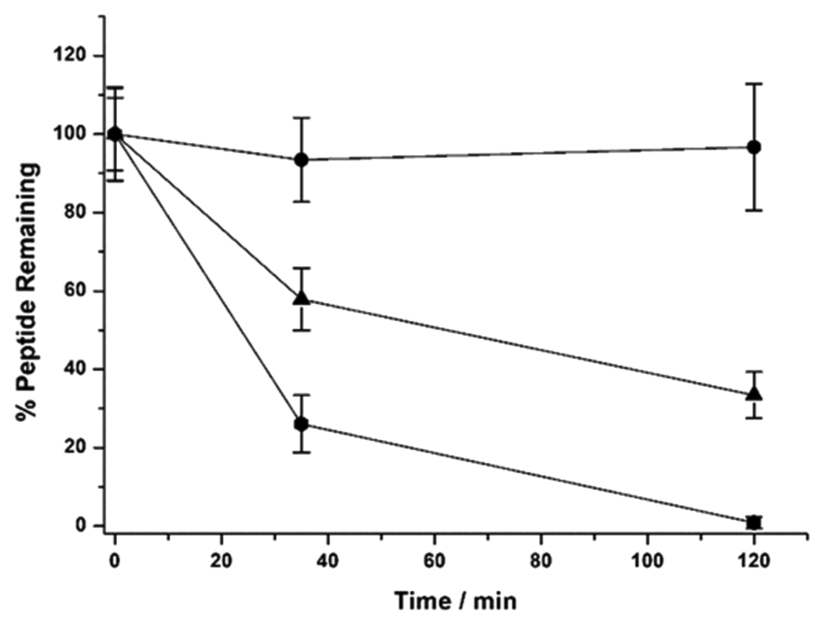

Figure 6. Serum stability profiles of $\mathrm{Gd}_{4}$-TESMA (circles), the VVGSpeptide (triangle), and a positive control peptide (square).

proteolysis of the peptide moiety and toward the deconjugation of the thioether bond and binding to other serum thiols. ${ }^{43}$ It is likely that the conjugation with the tetrameric gadolinium chelate prevented peptide digestion mediated by the $\mathrm{N}$ exopeptidases in the blood.

In Vivo MRI of Atherosclerotic Plaques in the $\mathrm{ApoE}^{-/-}$ Mouse Model Using $\mathrm{Gd}_{4}$-TESMA at a Clinical Field. The $\mathrm{Gd}_{4}$-TESMA probe was assessed for its ability to enhance the MRI signal within plaques in the brachiocephalic artery of an ApoE $^{->-}$murine model of plaque progression and in control nonatherosclerotic mice. For these studies, atherosclerotic $\mathrm{ApoE}^{-/-}$mice were scanned after the tandem administration of Gd-ESMA, Gd-TESMA (24 h after the Gd-ESMA administration), and finally $\mathrm{Gd}_{4}$-TESMA ( $24 \mathrm{~h}$ after the Gd-TESMA administration; Supporting Information Figure S1). Previous studies have shown that $24 \mathrm{~h}$ is sufficient to ensure the complete washout of Gd-ESMA and Gd-TESMA from the blood, plaques, and vessel walls. ${ }^{9}$ All molecular probes were injected at a dose of $0.2 \mathrm{mmol} \mathrm{kg} \mathrm{m}^{-1}$ (corresponding to the same dose of injected gadolinium for Gd-ESMA and GdTESMA and to a dose of $0.8 \mathrm{mmol}_{\mathrm{Gd}} \mathrm{kg}^{-1}$ for $\mathrm{Gd}_{4}$-TESMA). A $3 \mathrm{D}$ reconstructed $\mathrm{MR}$ angiogram shows the vasculature 
extending from the aortic root to the carotid arteries that defines the imaging volume (Figure $7 \mathrm{~A}$ ). Late gadolinium

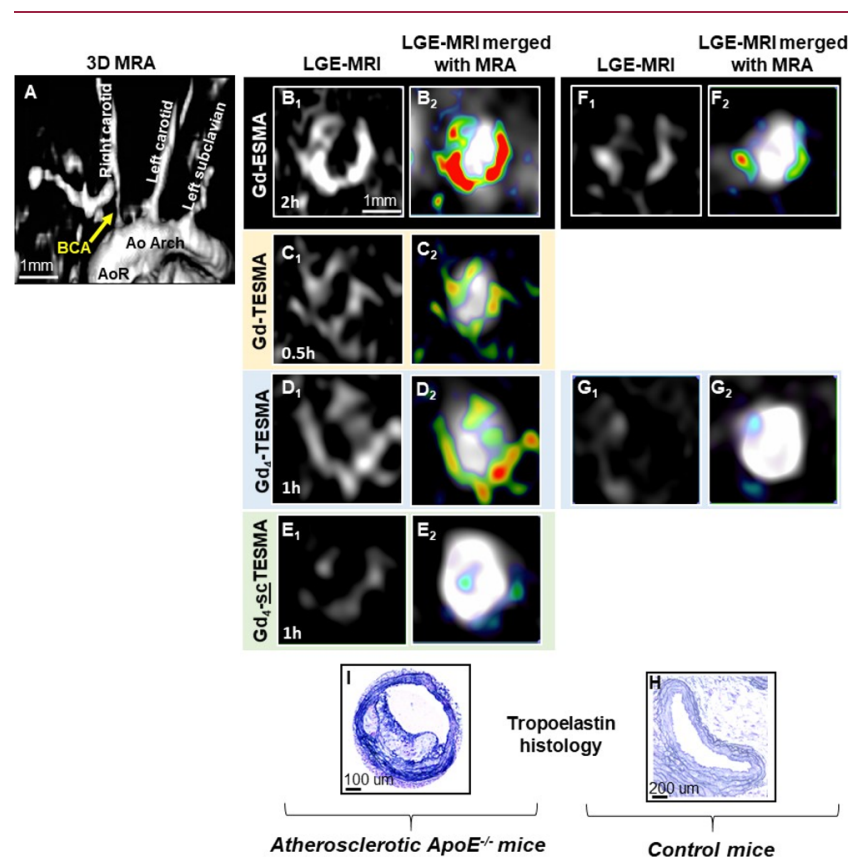

Figure 7. Molecular imaging of tropoelastin in atherosclerotic $\mathrm{ApoE}^{-/-}$and control mice using the tetrameric $\mathrm{Gd}_{4}$-TESMA contrast agent. (A) The $3 \mathrm{D}$ reconstructed angiogram (MRA) shows the vasculature. Late gadolinium enhancement (LGE) images $\left(B_{1}-D_{1}\right)$ and merged LGE and angiography images $\left(B_{2}-D_{2}\right)$ compare the signal enhancement of atherosclerotic plaques located in the brachiocephalic artery of the same animal imaged serially after the administration of the elastin-binding Gd-ESMA $(2 \mathrm{~h})$, the tropoelastin-binding Gd-TESMA $(0.5 \mathrm{~h})$, and the tropoelastinbinding tetrameric $\mathrm{Gd}_{4}$-TESMA $(1 \mathrm{~h})$ agents. $\left(\mathrm{E}_{1}, \mathrm{E}_{2}\right)$ LGE and merged images show a low uptake of the tetrameric tropoelastinbinding agent attached to a scrambled peptide ( $\mathrm{Gd}_{4}$-scTESMA). $\left(\mathrm{F}_{1}\right.$, $\mathrm{F}_{2}$ ) LGE and merged LGE and angiography images show signal enhancement of the brachiocephalic artery of control mice after the injection of the elastin agent Gd-ESMA but $\left(G_{1}, G_{2}\right)$ no enhancement after the injection of the tropoelastin agent $\mathrm{Gd}_{4}$-TESMA. Immunohistochemistry using a tropoelastin antibody shows the absence of tropoelastin in control tissues $(\mathrm{H})$ and dense tropoelastin molecules (dark/purple signal) in the disease artery (I).

enhanced (LGE) inversion recovery $T_{1}$-weighted images acquired at every $30 \mathrm{~min}$ postinjection of each agent allowed for the accurate detection and localization of atherosclerotic plaques and elastin/tropoelastin remodeling in the brachiocephalic artery. LGE images after administration of the GdESMA agent in $\mathrm{ApoE}^{-/-}$mice showed a strong circumferential enhancement of the plaque surrounding the lumen (Figure $7 \mathrm{~B} 1,2)$ that persisted up to $2 \mathrm{~h}$ postinjection. LGE images after the administration of the monomeric Gd-TESMA probe showed an enhancement of the same segment of the vessel wall. However, the area of the enhancement was less compared to that observed with Gd-ESMA, and the signal peaked at $0.5 \mathrm{~h}$ postinjection (Figure 7C1,2). Compared to Gd-TESMA, $\mathrm{Gd}_{4}$ TESMA showed a stronger enhancement of the plaque that peaked at $1 \mathrm{~h}$ postinjection (Figure 7D1,2). To check whether the uptake and retention within the plaques were specific of the targeting sequence, control experiments were carried out by using a probe containing a scrambled peptide sequence that is not able to recognize tropoelastin $\left(\mathrm{Gd}_{4}\right.$-scTESMA probe).
The scrambled $\mathrm{Gd}_{4}$-scTESMA showed low/negligible accumulation within plaques in comparison to $\mathrm{Gd}_{4}$-TESMA (Figure 7E1,2).

LGE images of the brachiocephalic artery acquired from healthy animals showed that Gd-ESMA delineates the vessel wall because it binds to cross-linked elastin that is endogenously present in healthy vessel wall (Figure $7 \mathrm{~F} 1,2$ ). Importantly, injection of $\mathrm{Gd}_{4}$-TESMA in heathy mice showed little accumulation of the agent within healthy vessel walls that are known to contain polymeric elastin but not monomeric tropoelastin (Figure 7G1,2). This conclusion drawn from the observed MRI signal was validated by immunohistochemistry of the excised tissues using a tropoelastin-specific antibody. There was a lack of immune-positive tropoelastin fibers in the control vessel wall (Figure $7 \mathrm{H}$ ), whereas a dense tropoelastin network (black/purple staining) was observed within the atherosclerotic plaque (Figure 7I).

Quantitative assessments of the MRI measurements in $\mathrm{ApoE}^{-/-}$and control mice are shown in Figure 8. All three compounds showed specific uptake in atherosclerotic plaques of $\mathrm{ApoE}^{-/-}$mice (Figure 8A) but with clear differences in wallto-blood CNR. Gd-ESMA had a peak CNR of 11.17 (interquartile range, IQR $=8.4-11.8) 2 \mathrm{~h}$ postinjection; GdTESMA had a maximum CNR of $6.75(\mathrm{IQR}=4.5-8.2)$ at 0.5 $\mathrm{h}$; and $\mathrm{Gd}_{4}$-TESMA had a maximum CNR of 10.47 (IQR = 6.3-10.6), 1.57-fold higher than that of Gd-TESMA, at $1 \mathrm{~h}$. While the CNR of Gd-TESMA was significantly decreased $1 \mathrm{~h}$ postinjection $(\mathrm{CNR}=1.58, \mathrm{IQR}=1.0-5.3)$, that of $\mathrm{Gd}_{4}$ TESMA was more persistent up to $2 \mathrm{~h}(\mathrm{CNR}=5.66, \mathrm{IQR}=$ 4.8-9.0), overall extending the duration of the imaging window from 0.5 to $2 \mathrm{~h}$. The vessel wall CNR measurements in control animals (Figure 8B) were significantly higher $2 \mathrm{~h}$ after the administration of Gd-ESMA compared to $1 \mathrm{~h}$ after the injection of Gd-TESMA and $\mathrm{Gd}_{4}$-TESMA, demonstrating that only Gd-ESMA can bind to the cross-linked elastin found in the control vessel $(\mathrm{CNR}=10, \mathrm{IQR}=9.9-11.5)$. Simultaneously, it demonstrates the specificity of the GdTESMA (CNR $=2.0, \mathrm{IQR}=1.8-2.5)$ and $\mathrm{Gd}_{4}$-TESMA (CNR $=3.0$, $\mathrm{IQR}=2.48-3.1)$ probes to only bind to non-crosslinked tropoelastin that is absent in control vessels.

In $\mathrm{ApoE}^{-/-}$mice, Gd-ESMA showed the largest enhancement area with $2.69 \mathrm{~mm}^{2}$ (IQR $\left.=1.7-6.9\right)$, while Gd-TESMA and $\mathrm{Gd}_{4}$-TESMA had smaller but comparable values of 0.87 $\mathrm{mm}^{2}(\mathrm{IQR}=0.78-3.56)$ and $1.3 \mathrm{~mm}^{2}(\mathrm{IQR}=0.77-2.48)$, respectively (Figure $8 \mathrm{C}$ ). The scrambled $\mathrm{Gd}_{4}$-scTESMA showed low/negligible accumulation within plaques in comparison to $\mathrm{Gd}_{4}$-TESMA in terms of enhanced area (0.1 $\left.\mathrm{mm}^{2}, \mathrm{IQR}=0-0.31\right)$. Similar to the CNR, the area of enhancement after administration of Gd-ESMA with $0.99 \mathrm{~mm}^{2}$ (IQR $=0.82-0.99)$ was the largest compared with that measured after the injection of Gd-TESMA $\left(0.38 \mathrm{~mm}^{2}, \mathrm{IQR}=\right.$ $0.28-0.43)$ and $\mathrm{Gd}_{4}$ TESMA $\left(0.26 \mathrm{~mm}^{2}, \mathrm{IQR}=0.24-0.32\right)$ in control animals (Figure $8 \mathrm{D}$ ). This is consistent with the fact that atherosclerotic plaques contain a mixture of mature elastin and tropoelastin, and Gd-ESMA is known to bind to both biological targets. ${ }^{20}$ Conversely, Gd-TESMA and $\mathrm{Gd}_{4}$-TESMA bind only to the subset of tropoelastin molecules within the plaque.

\section{DISCUSSION}

Gd-TESMA has been successfully employed for tropoelastin specific MR imaging by virtue of its ability to discriminate between tropoelastin and mature, cross-linked elastin. 
A

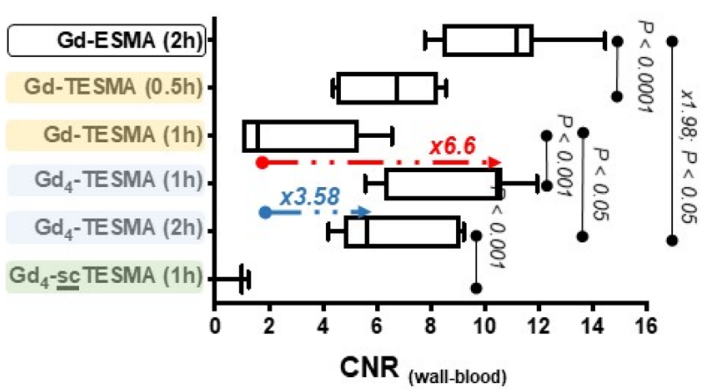

c

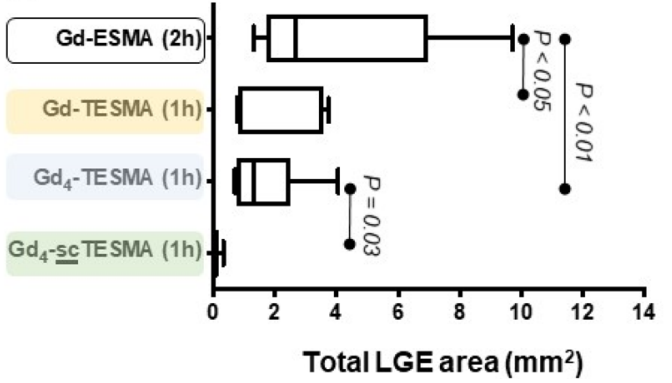

B

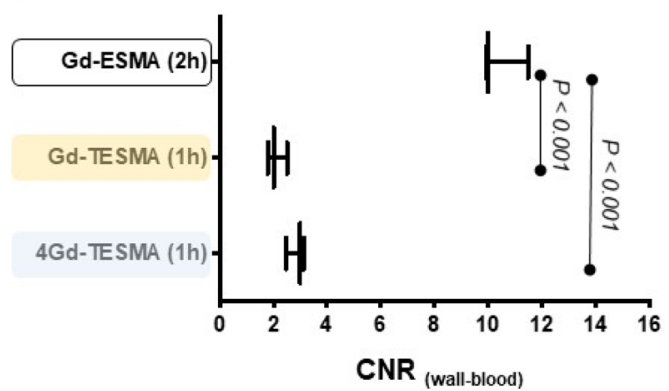

D

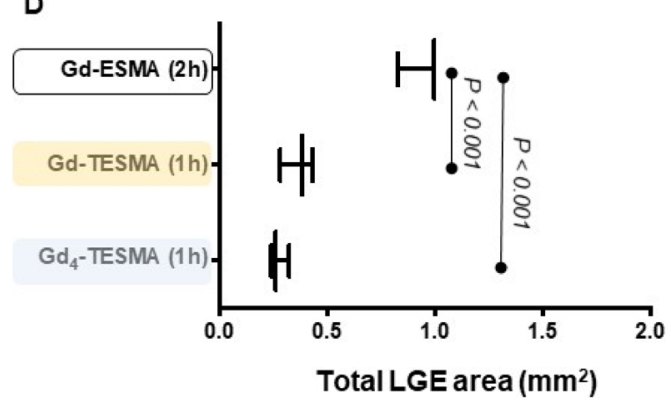

Figure 8. Quantitative assessments of the MRI measurements. Vessel wall-to-blood CNR at several time points after the injection of Gd-ESMA, Gd-TESMA, Gd ${ }_{4}$-TESMA, and $\mathrm{Gd}_{4}$-scTESMA (scrambled sequence as a negative control) in atherosclerotic ApoE ${ }^{-/-}$mice (A) and control mice (B). Total area showing late gadolinium enhancement (LGE) in atherosclerotic $\mathrm{ApoE}^{-/-}$mice (C) or control mice (D).

Tropoelastin imaging enables the in vivo assessment of dysfunctional elastogenesis that is in turn an emerging biomarker of atherosclerotic diseases. Tropoelastin provided a marker for MRI of atherosclerotic plaque progression and instability. ${ }^{9}$ It was also correlated with the development and rate of aortic expansion of aortic aneurysm. ${ }^{27}$

The scope of this study was to enhance the imaging properties of the Gd-TESMA probe to enable improved MR tropoelastin imaging (e.g., higher CNR and prolonged imaging window). The chosen strategy to achieve that goal was to link four paramagnetic gadolinium chelates to the tropoelastin specific VVGS-peptide to increase the relaxivity per molecule roughly by a factor of 4 . The chelate chosen to build up the tetrameric reporter unit is of the Gd-DOTA-monoamide type, as this macrocyclic ligand is known to have high thermodynamic, kinetic, and metabolic stability that minimizes transmetallation and gadolinium release issues. It is therefore preferred to other types of chelates for clinical translation. ${ }^{44,45}$

The relaxivity per molecule of $\mathrm{Gd}_{4}$-TESMA (HEPES saline buffer, $\mathrm{pH} 7.2,298 \mathrm{~K}, 20 \mathrm{MHz}$ ) is 3.4-fold greater than that of Gd-TESMA (at $1.0 \mathrm{mM}$ gadolinium concentration). This ratio is slightly smaller than the expected factor of 4 because of two reasons: $(i)$ the high flexibility of the $\mathrm{Gd}_{4}$-TESMA tetrameric moiety, avoiding the macromolecule effect on the relaxivity of $\mathrm{Gd}_{4}$-TESMA, and (ii) the aggregation of Gd-TESMA, but not of $\mathrm{Gd}_{4}$-TESMA, into molecular assemblies that in turn results into a slight concentration-dependent macromolecule effect.

The relaxivity per gadolinium $\left(8.5 \pm 0.2 \mathrm{mM}^{-1} \mathrm{~s}^{-1}\right)$ is in line with that of the free form of other multimeric Gd-DOTAmonoamide complexes based on a flexible scaffold. ${ }^{28,40}$ While Gd(III)-DOTA-monoamide multimers designed with rigid or cross-linked structures in the bound form are known to have a moderate relaxivity enhancement in comparison to the free form (macromolecule effect), $\mathrm{Gd}_{4}$-TESMA is expected to have a limited relaxivity enhancement in the tropoelastin bound form because of the high flexibility of the tetramer moiety.
While sacrificing the small relaxivity increase due to the macromolecule effect, flexibility was introduced in the probe design to minimize potential steric hindrance effects due to the bulky tetrameric Gd-DOTA moiety of the probe. Indeed, a good binding affinity between $\mathrm{Gd}_{4}$-TESMA and the biological target, tropoelastin, was maintained. Kinetic affinity measurements by SPR showed no substantial differences between the dissociation constants of Gd-TESMA and $\mathrm{Gd}_{4}$-TESMA.

In the atherosclerotic ApoE ${ }^{-/-}$mouse model, both GdTESMA and $\mathrm{Gd}_{4}$-TESMA were specifically retained in diseased atherosclerotic animals having plaques rich in tropoelastin. The specificity for such tropoelastin-rich regions was supported by two different control experiments: the scrambled version of $\mathrm{Gd}_{4}$-TESMA showing negligible accumulation within plaques and the $\mathrm{Gd}_{4}$-TESMA not accumulating in the healthy vessel wall, as previously also demonstrated for the monomeric Gd-TESMA. ${ }^{9}$ However, Gd $\mathrm{d}_{4}$-TESMA and Gd-TESMA showed a clear difference in their times required to reach the maximum CNR (Figure 8A). Gd-TESMA reached the maximum $\mathrm{CNR}$ in half an hour and then significantly decreased within $1 \mathrm{~h}$. Conversely, $\mathrm{Gd}_{4}$-TESMA reached the maximum CNR in $1 \mathrm{~h}$ p.i. and the CNR decreased by $46 \%$ after $2 \mathrm{~h}$. Importantly, the CNR of $\mathrm{Gd}_{4}$-TESMA at $2 \mathrm{~h}$ p.i. was still as high as the maximum CNR of Gd-TESMA at $0.5 \mathrm{~h}$. This difference in the pharmacokinetics reveals a clear benefit of $\mathrm{Gd}_{4}$-TESMA with respect to Gd-TESMA, allowing for a better delineation between the vessel wall and blood, increasing the sensitivity, and widening the imaging time window.

The $\mathrm{Gd}_{4}$-TESMA was rationally designed to image elastin related fibrosis with an eye to clinical translation. The DOTA chelator used in $\mathrm{Gd}_{4}$-TESMA is currently used in the most stable commercially available MRI contrast agent Gd-DOTA for which there are no reported cases of nephrogenic systemic fibrosis. The higher sensitivity and vessel wall delineation achieved by $\mathrm{Gd}_{4}$-TESMA may potentially allow for lowering the injected dose, thereby reducing both manufacturing costs 
and potential gadolinium effects. These improvements in vessel wall imaging made by using $\mathrm{Gd}_{4}$-TESMA combined with imaging protocols, such as the inversion recovery for late gadolinium enhancement, that are available on clinical scanners and have been used for imaging the heart and thrombosis in patients may facilitate the future use of the molecular imaging probe $\mathrm{Gd}_{4}$-TESMA for imaging dysfunctional elastogenesis in patients.

\section{CONCLUSIONS}

The modular and scalable chemistry of $\mathrm{Gd}_{4}$-TESMA, its immediate target localization after injection, its fast background washout, the increased signal enhancement, the elongated image acquisition window, and its high stability toward proteolysis and deconjugation in serum make $\mathrm{Gd}_{4}$ TESMA a desirable probe for molecular imaging of dysfunctional/dysregulated elastogenesis. The high CNR achieved by $\mathrm{Gd}_{4}$-TESMA increases the sensitivity for the detection of disease and treatment response, overcoming this major limitation of molecular MRI. It allows taking advantage of the higher spatial resolution, non-ionizing radiation, excellent soft tissue contrast, multiple image contrasts, and advanced motion correction protocols of MRI.

\section{EXPERIMENTAL SECTION}

General Methods. Bis(2-aminoethyl)ether trityl resin, PyBOP (benzotriazol-1-yloxytripyrrolidinophosphonium hexafluorophosphate), Fmoc-Lys(Fmoc)-OH, and all other Fmoc-AA-OH were purchased from Novabiochem (Darmstadt, Germany). Gd-TESMA was purchased from For Peptide Protein Research Limited (Fareham, UK). All other chemicals were purchased from Sigma-Aldrich. NMR spectra were recorded at $310 \mathrm{~K}$ on a Bruker AVANCE 600 spectrometer operating at $14 \mathrm{~T}$ (corresponding to 600 and 150 $\mathrm{MHz}{ }^{1} \mathrm{H}$ and ${ }^{13} \mathrm{C}$ Larmor frequencies, respectively). Analytical and preparative HPLC-MS was carried out on a Waters AutoPurification system (3100 Mass Detector, 2545 Pump Gradient Module, 2767 Sample Manager, and 2998 PDA detector). ESI+ mass spectra were calculated as the exact mass by considering the ${ }^{158} \mathrm{Gd}$ isotope for gadolinium complexes. UPLC analysis was performed using a UPLC Acquity H-Class coupled with the $\mathrm{QDa}$ and TUV detectors. All compounds are $>95 \%$ pure by HPLC.

Synthesis of [DOTA $]_{4}-\mathrm{NH}_{2}$. The synthesis of $[\text { DOTA }]_{4}-\mathrm{NH}_{2}$ was performed on the solid phase manually by using bis(2-aminoethyl)ether trityl resin $(0.96 \mathrm{mmol} ; 1.95 \mathrm{~g})$ in a peptide synthesis vessel. After swelling in dimethylformamide (DMF) $(25 \mathrm{~mL})$ for $10 \mathrm{~min}$, Fmoc-Lys(Fmoc)-OH (2.39 mmol; $1.41 \mathrm{~g}$ ), PyBOP (2.39 mmol; 1.24 $\mathrm{g}$ ), and $\mathrm{N}, \mathrm{N}$-diisopropylethylamine (DIPEA) $(4.78 \mathrm{mmol} ; 0.83 \mathrm{~mL})$ in DMF $(20 \mathrm{~mL})$ were added and the reaction slurry was shaken at room temperature for $1 \mathrm{~h}$ followed by a capping reaction with $20 \%$ acetic anhydride in DMF $(20 \mathrm{~mL})$. The resin was washed with DMF $(3 \times 25 \mathrm{~mL})$ and then treated with $20 \mathrm{~mL} 40 \%$ piperidine/DMF (5 $\min )$ and $20 \mathrm{~mL} 20 \%$ piperidine/DMF solution for $15 \mathrm{~min}(\times 2)$ to remove Fmoc protecting groups. After washing with DMF, the coupling cycle was repeated using a double quantity of FmocLys(Fmoc)-OH (4.78 mmol; $2.82 \mathrm{~g}$ ), PyBOP (4.78 mmol; $2.49 \mathrm{~g}$ ), and DIPEA ( $9.55 \mathrm{mmol} ; 1.67 \mathrm{~mL})$ in DMF $(20 \mathrm{~mL})$ followed by piperidine treatment. After washing with DMF, a mixture of $\operatorname{DOTA}(t \mathrm{Bu})_{3} \mathrm{CONH}\left(\mathrm{CH}_{2}\right)_{5} \mathrm{COOH}^{33}(4.02 \mathrm{mmol} ; 2.76 \mathrm{~g})$, PyBOP $(4.01 \mathrm{mmol} ; 2.09 \mathrm{~g})$, and DIPEA $(8.02 \mathrm{mmol} ; 1.40 \mathrm{~mL})$ in DMF $(20$ $\mathrm{mL}$ ) was added and the reaction was shaken at room temperature for $2 \mathrm{~h}$. The resin was washed with DMF $(3 \times 20 \mathrm{~mL})$ and DCM $(3 \times 20$ $\mathrm{mL}$ ) and then treated with $10 \mathrm{~mL}$ of $50 \%$ TFA in DCM plus $2 \%$ of triisopropylsilane (TIS) for $20 \mathrm{~min}$ at room temperature. The TFA solution was collected, and the resin was washed with $10 \%$ TFA in DCM $(5 \mathrm{~mL})$. The combined extracts were concentrated under reduced pressure; then $20 \mathrm{~mL}$ of fresh TFA was added, and the mixture was stirred for $12 \mathrm{~h}$ to ensure the complete removal of $t \mathrm{Bu}$ from DOTA chelators. The cleavage solution was concentrated under reduced pressure, and the crude product was precipitated in cold $\mathrm{Et}_{2} \mathrm{O}$ $(20 \mathrm{~mL})$ and purified by semipreparative RP-HPLC by using a Waters XTerra prep RPdC8 column, $5 \mu \mathrm{m}, 19 \times 100 \mathrm{~mm}$, with a gradient of $\mathrm{CH}_{3} \mathrm{CN}\left(0.1 \%\right.$ TFA) in $\mathrm{H}_{2} \mathrm{O}$ (0.1\% TFA) from 5 to $10 \%$ in $3 \mathrm{~min}$ and from 10 to $35 \%$ in $12 \mathrm{~min}\left(20 \mathrm{~mL} \mathrm{~min}^{-1}\right)$. The pure product was obtained as a TFA salt (white powder) by lyophilization. The pure product was obtained as a white powder ( $1.2 \mathrm{~g}, 50 \%$ of yield). The purity of the tetrameric compound was verified by analytical UPLC using an ACQUITY UPLC Peptide BEH C18 column, $1.7 \mu \mathrm{m}, 2.1 \times$ $150 \mathrm{~mm}$, applying a gradient of $\mathrm{CH}_{3} \mathrm{CN}(0.05 \% \mathrm{TFA})$ in $\mathrm{H}_{2} \mathrm{O}(0.05 \%$ TFA) from 5 to $20 \%$ in $10 \mathrm{~min}$ and from 20 to $80 \%$ in $12 \mathrm{~min}(0.4$ $\left.\mathrm{mL} \mathrm{min}^{-1}\right)$. The purity was $>95 \%$ based on the chromatographic peak area revealed at $220 \mathrm{~nm}$ (retention time $3.7 \mathrm{~min}$ ). ESI + MS m/z (calcd. for $\mathrm{C}_{110} \mathrm{H}_{196} \mathrm{~N}_{28} \mathrm{O}_{36}$ ): $[\mathrm{M}+3 \mathrm{H}]^{3+} 829.8$ (obsd.), 829.8 (calcd.); $[\mathrm{M}+4 \mathrm{H}]^{4+} 622.7$ (obsd.), 622.6 (calcd.); $[\mathrm{M}+5 \mathrm{H}]^{5+} 498.3$ (obsd.), 498.3 (calcd.) See Supporting Information Figure S2 for UPLC-UV-ESI-MS and Figure S3 for ${ }^{1} \mathrm{H}$ NMR.

Synthesis of [Gd-DOTA $]_{4}-\mathrm{NH}_{2}$. An equimolar amount of $\mathrm{GdCl}_{3}$. $6 \mathrm{H}_{2} \mathrm{O}(0.24 \mathrm{mmol} ; 89.2 \mathrm{mg})$ was slowly added to the ligand solution $(0.06 \mathrm{mmol} ; 149.2 \mathrm{mg})(5 \mathrm{~mL})$. The $\mathrm{pH}$ of the solution was adjusted to 6.5 with $\mathrm{NaOH}$, and the mixture was stirred overnight. The Gdcomplex was then desalted by size exclusion chromatography on PD10 Desalting Columns prepacked with Sephadex G25, using Milli-Q water as the mobile phase, and finally freeze-dried. The amount of residual free $\mathrm{Gd}^{3+}$ ions was assessed by the Orange Xylenol UV method. ${ }^{46}[\mathrm{Gd}-\mathrm{DOTA}]_{4}-\mathrm{NH}_{2}$ was found to contain less than $0.3 \%$ $(\mathrm{mol} / \mathrm{mol})$ of residual free $\mathrm{Gd}^{3+}$ ions. The purity of $[\mathrm{Gd}-\mathrm{DOTA}]_{4}$ $\mathrm{NH}_{2}$ was checked by using the same analytical UPLC method described for $[\text { DOTA }]_{4}-\mathrm{NH}_{2}$ (retention time $3.5 \mathrm{~min}$ ). The purity was $>95 \%(\lambda=220 \mathrm{~nm})$. ESI + MS $m / z$ (calcd. for $\left.\mathrm{C}_{110} \mathrm{H}_{184} \mathrm{Gd}_{4} \mathrm{~N}_{28} \mathrm{O}_{36}\right):[\mathrm{M}+3 \mathrm{H}]^{3+} 1035.6$ (obsd.), 1035.3 (calcd.); $[\mathrm{M}+4 \mathrm{H}]^{4+} 776.9$ (obsd.), 776.9 (calcd.) (see Supporting Information Figure S4).

Synthesis of $[\mathrm{Gd}-\mathrm{DOTA}]_{4}$-MI. $\mathrm{N}$-Succinimidyl-3-maleimido propionate $\left(0.06 \mathrm{mmol} ; 16 \mathrm{mg}\right.$ ) dissolved in $1 \mathrm{~mL}$ of $\mathrm{CH}_{3} \mathrm{CN}$ was slowly added to a solution of [Gd-DOTA $]_{4}-\mathrm{NH}_{2}(0.02 \mathrm{mmol} ; 50 \mathrm{mg})$ in buffer phosphate ( $50 \mathrm{mM} ; 3 \mathrm{~mL}$; $\mathrm{pH} 6.7$ ). After stirring for $60 \mathrm{~min}$ at room temperature, the organic phase was evaporated and then desalted and purified by Sephadex G-25 in a PD-10 Desalting Column against water. The fractions containing the purified product were collected and lyophilized ( $36.6 \mathrm{mg}, 73.2 \%$ of yield). The purity of $[\text { Gd-DOTA }]_{4}-\mathrm{NH}_{2}$ was checked by using the same analytical UPLC method described for $[\text { DOTA }]_{4}-\mathrm{NH}_{2}$ (retention time $4.5 \mathrm{~min}$ ). The purity was $>88 \%(\lambda=220 \mathrm{~nm})$. ESI + MS $\mathrm{m} / z$ (calcd. for $\mathrm{C}_{117} \mathrm{H}_{189} \mathrm{Gd}_{4} \mathrm{~N}_{29} \mathrm{O}_{39}$ ): $[\mathrm{M}+3 \mathrm{H}]^{3+} 1086.3$ (obsd.), 1085.9 (calcd.); $[\mathrm{M}+4 \mathrm{H}]^{4+} 814.5$ (obsd.), 814.7 (calcd.) (Supporting Information Figure S5).

Synthesis of the C-VVGS Peptide. The 16-mer peptide sequence CVVGSPSAQDEASPLS (C-VVGS peptide), containing the tropoelastin binding motif, was performed manually by standard Fmoc solid-phase peptide synthesis on the 2-chlorotrityl chloride resin $(500 \mathrm{mg}, 0.8 \mathrm{mmol}$, loading: $1.60 \mathrm{mmol} / \mathrm{g})$. Each reaction step was performed at room temperature under gentle stirring. Amino acid coupling reactions were performed using 2.5 equiv of the Fmocprotected amino acid, 2.5 equiv of the activating agent (PyBOP), and 5 equiv of the base (DIPEA) in DMF for $30 \mathrm{~min}$. Fmoc removal was performed using a solution of $20 \%$ piperidine in DMF twice for 10 min. The resin was washed with DMF after each reaction step. Final cleavage and deprotection were performed with a solution of trifluoracetic acid (TFA) $/ \mathrm{H}_{2} \mathrm{O} /$ phenol/triisopropylsilane (88:5:5:2, $\mathrm{v} / \mathrm{v} / \mathrm{wt} / \mathrm{v}$ ) for $3 \mathrm{~h}$ at room temperature. $\mathrm{Et}_{2} \mathrm{O}$ was added, and the precipitated crude product was collected and dried. The crude peptide was then dissolved in water and purified by semipreparative RPHPLC by using a Waters XTerra prep RPdC 8 column, $5 \mu \mathrm{m}, 19 \times$ $100 \mathrm{~mm}$, with a gradient of $\mathrm{CH}_{3} \mathrm{CN}(0.1 \% \mathrm{TFA})$ in $\mathrm{H}_{2} \mathrm{O}(0.1 \% \mathrm{TFA})$ from 5 to $10 \%$ in $3 \mathrm{~min}$ and from 10 to $35 \%$ in $12 \min \left(20 \mathrm{~mL} \mathrm{~min}^{-1}\right)$ and lyophilized to give peptide as a white powder $(0.62 \mathrm{~g}$, TFA salt, $50 \%$ yield based on the estimated loading of the resin). The purity of the peptide was verified by analytical HPLC using an Atlantis C18, 3.5 
$\mu \mathrm{m}, 4.6 \mathrm{~mm} \times 150 \mathrm{~mm}$ column and $0.1 \%$ TFA in water (solvent A) and $0.1 \%$ TFA in acetonitrile (solvent B); elution was done with a linear 5 to $55 \%$ gradient of solvent B into A over $40 \mathrm{~min}$ at a $1 \mathrm{~mL}$ $\mathrm{min}^{-1}$ flow rate with UV detection at 220 and $254 \mathrm{~nm}$ (retention time $=14.8 \mathrm{~min}$, purity $>98 \%, \lambda=220 \mathrm{~nm}$ ). ESI $+\mathrm{MS} \mathrm{m} / z$ (calcd. for $\mathrm{C}_{63} \mathrm{H}_{102} \mathrm{~N}_{17} \mathrm{O}_{27} \mathrm{~S}$ ): $[\mathrm{M}+2 \mathrm{H}]^{2+} 773.8$ (obsd.), 774.3 (calcd.); $[\mathrm{M}+$ $\mathrm{H}^{2+} 1547.3$ (obsd.), 1547.6 (calcd.) (Supporting Information Figure S6). The scrambled peptide (C-GAESAPLVSSVQSPD) was synthetized following the same synthetic procedure of the C-VVGS peptide. HPLC analysis: retention time $=14.8 \mathrm{~min}$, purity $>98 \%(\lambda=$ $220 \mathrm{~nm})$. ESI $+\mathrm{MS} m / z$ (calcd. for $\left.\mathrm{C}_{63} \mathrm{H}_{102} \mathrm{~N}_{17} \mathrm{O}_{27} \mathrm{~S}\right):[\mathrm{M}+2 \mathrm{H}]^{2+}$ 773.9 (obsd.), 774.3 (calcd.); $[\mathrm{M}+\mathrm{H}]^{+} 1547.5$ (obsd.), 1547.6 (calcd.)

Synthesis of $\mathrm{Gd}_{4}$-TESMA. A solution of the C-VVGS peptide $(0.03 \mathrm{mmol} ; 47 \mathrm{mg})$ in acetate buffer $(0.1 \mathrm{M} ; 2 \mathrm{~mL}$; $\mathrm{pH} 6.7)$ was slowly added to a solution of [Gd-DOTA $]_{4}$-MI $(0.03 \mathrm{mmol} ; 100 \mathrm{mg})$ in water $(2 \mathrm{~mL})$ under an argon atmosphere. The mixture was stirred at room temperature for $1 \mathrm{~h}$. The crude product was purified by preparative RP-HPLC using an Atlantis prep RPdC18 column, $5 \mu \mathrm{m}$, $19 \times 100 \mathrm{~mm}$, with a gradient of $\mathrm{CH}_{3} \mathrm{CN}$ in $10 \mathrm{mM}$ ammonium acetate from 5 to $35 \%$ in $30 \mathrm{~min}\left(20 \mathrm{~mL} \mathrm{~min}^{-1}\right)$. Finally, the purified product was desalted by gel permeation chromatography with Sephadex G10 and lyophilized (62 mg, 43\% yield). The purity of $\mathrm{Gd}_{4}$-TESMA was evaluated by analytical HPLC using an Atlantis C18 column by the same method described for C-VVGS peptide. Retention time was $14.8 \mathrm{~min}$, and the purity of the compound $>95 \%(\lambda=220 \mathrm{~nm})$. ESI $+\mathrm{MS} m / z\left(\right.$ calcd. for $\left.\mathrm{C}_{180} \mathrm{H}_{292} \mathrm{Gd}_{4} \mathrm{~N}_{46} \mathrm{O}_{65} \mathrm{~S}\right)$ : $[\mathrm{M}+5 \mathrm{H}]^{5+} 962.1$ (obsd.), 961.3; $[\mathrm{M}+4 \mathrm{H}]^{4+} 1201.4$ (obsd.), 1201.4 (calcd); $[\mathrm{M}+3 \mathrm{H}]^{3+} 1602.0$ (obsd.), 1601.6 (calcd) (Supporting Information Figure $\mathrm{S} 7$ ). The scrambled $\mathrm{Gd}_{4}$-scTESMA was synthetized following the same synthetic procedure of $\mathrm{Gd}_{4}$-TESMA. HPLC analysis: retention time $=15.0 \mathrm{~min}$, purity $>98 \%(\lambda=220$ $\mathrm{nm})$. ESI + MS $m / z$ (calcd. for $\left.\mathrm{C}_{180} \mathrm{H}_{292} \mathrm{Gd}_{4} \mathrm{~N}_{46} \mathrm{O}_{65} \mathrm{~S}\right):[\mathrm{M}+5 \mathrm{H}]^{5+}$ 960.8 (obsd.), 961.3 (calcd.); $[\mathrm{M}+4 \mathrm{H}]^{4+} 1201.4$ (obsd.), 1201.4 (calcd); $[\mathrm{M}+3 \mathrm{H}]^{3+} 1603.4$ (obsd.), 1601.6 (calcd).

Relaxometry. The water proton longitudinal relaxation rates as a function of the magnetic field strength were measured in aqueous solutions using a Fast Field-Cycling Stelar SmarTracer relaxometer (Stelar s.r.l., Mede (PV), Italy) over a continuum of magnetic field strengths from 0.00024 to $0.25 \mathrm{~T}$ (corresponding to $0.01-10 \mathrm{MHz}$ proton Larmor frequencies). The relaxometer operates under computer control with an absolute uncertainty in $1 / T_{1}$ of $1 \%$. Additional longitudinal relaxation data in the range of $20-70 \mathrm{MHz}$ were obtained using a Stelar Relaxometer connected to a Bruker WP80 NMR electromagnet adapted to variable-field measurements. The ${ }^{1} \mathrm{H} T_{1}$ relaxation times were acquired by the standard inversion recovery method with a typical $90^{\circ}$ pulse width of $3.5 \mu \mathrm{s}, 16$ experiments, and 4 scans. The temperature was controlled using a Stelar VTC-91 airflow heater equipped with a calibrated copperconstantan thermocouple (uncertainty of $\pm 0.1{ }^{\circ} \mathrm{C}$ ).

Stability in Plasma. The serum stabilities of $\mathrm{Gd}_{4}$-TESMA and its parent peptide (VVGS-peptide) were determined in $50 \%(\mathrm{v} / \mathrm{v})$ aqueous pooled serum from human male $\mathrm{AB}$ plasma, which was purchased from Sigma-Aldrich (Milan, Italy). Samples were dissolved in water $(6.6 \mathrm{mM})$, diluted in serum (previously centrifuged at 8000 $\mathrm{rpm}$ for $15 \mathrm{~min}$ at $\left.4{ }^{\circ} \mathrm{C}\right)$ at a final concentration of $0.6 \mathrm{mM}(220 \mu \mathrm{L})$, and subsequently incubated at $37^{\circ} \mathrm{C}$. Aliquots $(6 \mu \mathrm{L})$ taken after 0 , 35 , and $120 \mathrm{~min}$ were diluted in water at a final concentration of 0.06 $\mathrm{mM}$. The samples were analyzed by RP-HPLC using an Atlantis $\mathrm{dC} 18$ column, $5 \mu \mathrm{m}, 4.6 \times 150 \mathrm{~mm}$, as described in ref 47 . The amount of intact compound was estimated by integrating the area under the corresponding elution peak monitored at $210 \mathrm{~nm}$. Five replicate experiments for each compound were carried out. The KQLLWIRSGDRPWYYTS (HPLW peptide), ${ }^{47}$ unrelated to TESMA, was used as a positive control.

Surface Plasmon Resonance Measurement of Binding Affinity. The binding affinity between tropoelastin (human recombinant tropoelastin, Advanced BioMatrix, Cat. No. 50521MG, Batch No. 7932) and Gd $_{4}$-TESMA or Gd-TESMA was assessed by surface plasmon resonance (SPR) on a Biacore 2000 instrument (Cytiva). The instrument was equipped with a CM5 sensor chip carrying carboxymethylated dextran (Cytiva). First, the ligand was immobilized on the sensor chip surface by amine coupling: the flow cell was activated for $7 \mathrm{~min}$ by a 1-ethyl-3-(3dimethylaminopropyl)carbodiimide hydrochloride (EDC)/ $N$-hydroxysuccinimide (NHS) mixture. Then, tropoelastin was injected at 200 $\mu \mathrm{M}$ in a $10 \mathrm{mM}$ sodium acetate buffer $(\mathrm{pH} 4)$ with a flow rate of $5 \mu \mathrm{L}$ $\mathrm{min}^{-1}$ to reach an immobilization level corresponding to $3500-5000$ resonance units (R.U.). The remaining active sites were blocked by 1 $\mathrm{M}$ of ethanolamine- $\mathrm{HCl}(\mathrm{pH} 8.5)$ for $7 \mathrm{~min}$. As a control for nonspecific interaction, another flow cell on the CM5 sensor chip was treated in the same manner but without adding tropoelastin. For the binding assay, the analyte was injected at $20 \mu \mathrm{L} \mathrm{min}^{-1}$ for 3 min at 25 ${ }^{\circ} \mathrm{C}$ and at different concentrations in the HEPES running buffer ( $\mathrm{pH}$ 7.4, HBS-P, Cytiva) or $10 \mathrm{mM}$ HEPES solution. This step was followed by a dissociation period of $2.5 \mathrm{~min}$ under the running buffer. The surface was regenerated by flowing $5 \mathrm{mM} \mathrm{NaOH} / 1 \mathrm{M} \mathrm{NaCl}$ for $30-60 \mathrm{~s}$ at $30 \mu \mathrm{L} \mathrm{min}{ }^{-1}$. A stabilization period of $4 \mathrm{~min}$ with the running buffer completed the cycle. The equilibrium dissociation constant $\left(K_{\mathrm{D}}\right)$ and the kinetic association and dissociation rate constants $\left(k_{\mathrm{a}}\right.$ and $\left.k_{\mathrm{d}}\right)$ were determined by curve-fitting using the $1: 1$ Langmuir binding model implemented in the Biaevaluation software 4.1.1. ${ }^{48}$ Before calculations, the nonspecific signal of the control channel was subtracted from the signal obtained from the functionalized channel.

Murine Model of Atherosclerosis Progression. Male apolipoprotein E knockout $\left(\mathrm{ApoE}^{-/}\right)(n=7)$ mice and wild-type C57BL/6J mice $(n=3)$ were purchased from Charles Rivers Laboratories (Edinburgh, UK). Eight-week-old $\mathrm{ApoE}^{-/-}$mice were switched to a high-fat diet (HFD) containing 21\% fat from lard and $0.15 \%$ (wt/wt) cholesterol (Special Diets Services, Witham, UK). ApoE ${ }^{-/-}$mice were imaged at 16 weeks after HFD feeding. Age- and gender-matched wild-type mice were fed a normal chow diet for 16 weeks and were used as controls.

In Vivo Imaging of Tropoelastin at $3 \mathrm{~T}$. All imaging experiments were performed using a $3 \mathrm{~T}$ Philips Achieva MR scanner (Philips Healthcare, Best, the Netherlands) equipped with a clinical gradient system $\left(30 \mathrm{mT} \mathrm{m}^{-1}, 200 \mathrm{mT} \mathrm{m}^{-1} \mathrm{~ms}^{-1}\right)$. Mice were imaged using a single-loop surface coil (diameter $=23 \mathrm{~mm})$. Anesthesia was induced with $4-5 \%$ and maintained with $1-2 \%$ isoflurane during the MRI experiments. Anesthetized animals were placed in the prone position, and the brachiocephalic artery (BCA) was imaged. The BCA of atherosclerotic mice was scanned three times on 3 consecutive days. On day 1 , mice were scanned up to $2 \mathrm{~h}$ after injection of GdESMA $\left(0.2 \mathrm{mmol} \mathrm{kg}^{-1}\right)$. On day 2, the same animals were scanned up to $2 \mathrm{~h}$ postinjection of the monomeric tropoelastin-binding contrast agent Gd-TESMA $\left(0.2 \mathrm{mmol} \mathrm{kg}{ }^{-1}\right)$. On day 3, the same mice were scanned up to $2 \mathrm{~h}$ postinjection of the tetrameric tropoelastin-binding contrast agent $\mathrm{Gd}_{4}$-TESMA $\left(0.2 \mathrm{mmol} \mathrm{kg}{ }^{-1}\right)$. Twenty-four hours later, a subgroup of atherosclerotic mice $(n=3)$ was imaged up to $2 \mathrm{~h}$ after injection of the scrambled $\mathrm{Gd}_{4}$-TESMA $\left(\mathrm{Gd}_{4^{-} \text {sc }}\right.$ TESMA; 0.2 mmol $\left.\mathrm{kg}^{-1}\right)$. Lastly, healthy control mice were scanned twice, on day 1 with Gd-ESMA and on day 3 with $\mathrm{Gd}_{4}$-TESMA, as described above. All injections were done intravenously.

In Vivo MRI Protocol. Following a 3D GRE scout scan, contrastenhanced angiography images were acquired for visualization of the aortic root, aortic arch, and brachiocephalic and carotid arteries with a FOV $=30 \times 30 \times 8 \mathrm{~mm}$, matrix $=200 \times 200$, in-plane resolution $=$ $0.15 \times 0.15 \mathrm{~mm}$ (reconstructed $=0.10 \times 0.10 \mathrm{~mm})$, slice thickness $=$ $0.5 \mathrm{~mm}, \mathrm{TR} / \mathrm{TE}=15 / 6.1(\mathrm{~ms})$, and flip angle $=40^{\circ}$. The maximum intensity projection images were used to plan the subsequent late gadolinium enhanced (LGE) MRI. A 2D Look-Locker sequence planned perpendicular to the ascending aorta was used to determine the optimal inversion time $(\mathrm{TI})$ for blood signal nulling with a FOV = $30 \times 30 \mathrm{~mm}$, matrix $=80 \times 80$, in-plane resolution $=0.38 \times 0.38 \mathrm{~mm}$, slice thickness $=2 \mathrm{~mm}, \mathrm{TR} / \mathrm{TE}=19 / 8.6(\mathrm{~ms})$, TR between subsequent IR pulses $=1000 \mathrm{~ms}$, and flip angle $=10^{\circ}$. Late gadolinium enhanced images were acquired with an inversionrecovery $3 \mathrm{D}$ fast gradient echo sequence every $30 \mathrm{~min}$ for up to 2 $\mathrm{h}$ postinjection of the contrast agent and were used to visualize and 
quantify contrast uptake. The FOV extended from the aortic root to the carotid arteries. Imaging parameters were FOV $=30 \times 30 \times 8$ $\mathrm{mm}$, matrix $=304 \times 304$, in-plane resolution $=0.1 \times 0.1 \mathrm{~mm}$, measured slice thickness $=0.5 \mathrm{~mm}$, slices $=32$, TR $/ \mathrm{TE}=28 / 8(\mathrm{~ms})$, TR between subsequent IR pulses $=1000 \mathrm{~ms}$, and flip angle $=30^{\circ}$.

MRI Image Analyses. The vessel wall area was calculated by manually segmenting the visually enhanced region of the vessel wall as seen on the LGE-MRI images using OsiriX (OsiriX Foundation, Geneva, Switzerland). To ensure that the segmented area encompassed the vessel wall, the LGE-MRI images were co-registered and fused with the magnetic resonance angiography images. The sum of LGE volume was calculated by adding the LGE area on each slice, encompassing the $\mathrm{BCA}$, and multiplying by the slice thickness. The contrast-to-noise ratio (CNR) between the vessel and blood was calculated as $\mathrm{CNR}=\left(\mathrm{SI}_{\text {wall }}-\mathrm{SI}_{\text {blood }}\right) / \mathrm{SD}_{\text {noise. }} . \mathrm{SI}=$ signal intensity and $\mathrm{SD}=$ standard deviation outside the body. The mean CNR in each animal is presented in the Results section.

Histology. The aortic root, aortic arch, and brachiocephalic and carotid arteries of diseased and control mice were removed en bloc, pinned down to maintain the tissue morphology, and fixed in $10 \%$ formaldehyde for $48 \mathrm{~h}$ at $4{ }^{\circ} \mathrm{C}(n=3)$. Tissues were embedded in paraffin and sectioned transversely ( $5 \mu \mathrm{m}$ thick). Immunohistochemistry for tropoelastin was performed using an anti-mouse rabbit polyclonal antibody (1:100, Abcam, ab21600, Cambridge, MA, USA).

Statistical Analysis. The relaxivities of the gadolinium complexes are expressed as mean \pm SD. Multiple-group comparisons for repeated MRI measurements were performed using a Friedman test. MRI data are presented as median \pm interquartile range (IQR). Statistical analysis was performed using PRISM (GraphPad Software, Inc., La Jolla, California). $P$ values $<0.05$ were considered statistically significant.

\section{ASSOCIATED CONTENT}

\section{(3) Supporting Information}

The Supporting Information is available free of charge at https://pubs.acs.org/doi/10.1021/acs.jmedchem.1c01286.

Experimental design of the MRI study of $\mathrm{Gd}_{4}$-TESMA in vivo; HPLC traces, ESI+ MS, and NMR spectra of final products and reaction intermediates (PDF)

\section{AUTHOR INFORMATION}

\section{Corresponding Author}

Giuseppe Digilio - Department of Science and Technologic Innovation, Università del Piemonte Orientale "Amedeo Avogadro", Alessandria 15121, Italy; ㅇo이.org/00000003-2397-2913; Email: giuseppe.digilio@uniupo.it

\section{Authors}

Federico Capuana - Department of Molecular Biotechnology and Health Sciences, University of Turin, Turin 10126, Italy

Alkystis Phinikaridou - School of Biomedical Engineering and Imaging Sciences, King's College London, London SE1 7EH, United Kingdom

Rachele Stefania - Department of Molecular Biotechnology and Health Sciences, University of Turin, Turin 10126, Italy

Sergio Padovan - Institute for Biostructures and Bioimages (CNR) c/o Molecular Biotechnology Center, Torino 10126, Italy

Begoña Lavin - School of Biomedical Engineering and Imaging Sciences, King's College London, London SE1 7EH, United Kingdom; Department of Biochemistry and Molecular Biology, School of Chemistry, Complutense University, Ciudad Universitaria $s / n$, Madrid 28040, Spain

Sara Lacerda - Centre de Biophysique Moléculaire, CNRS, UPR 4301, Université d'Orléans, Orléans Cedex 2 45071, France
Eyad Almouazen - CNRS, LAGEPP UMR 5007, Univ Lyon, Université Claude Bernard Lyon 1, Villeurbanne 69622, France

Yves Chevalier - CNRS, LAGEPP UMR 5007, Univ Lyon, Université Claude Bernard Lyon 1, Villeurbanne 69622, France; (1) orcid.org/0000-0002-7526-5658

Laurence Heinrich-Balard - INSA Lyon, CNRS, MATEIS, UMR5510, Univ Lyon, Université Claude Bernard Lyon 1, Villeurbanne 69100, France

René M. Botnar - School of Biomedical Engineering and Imaging Sciences, King's College London, London SE1 7EH, United Kingdom; Escuela de Ingeniería, Pontificia Universidad Católica de Chile, Santiago 4860, Chile

Silvio Aime - IRCCS SDN, Napoli 80100, Italy

Complete contact information is available at:

https://pubs.acs.org/10.1021/acs.jmedchem.1c01286

\section{Author Contributions}

${ }^{\S}$ F.C. and A.P. contributed equally to this work.

\section{Notes}

The authors declare no competing financial interest.

\section{ACKNOWLEDGMENTS}

This project has received funding from the EU's H2020 research and innovation program under the grant agreement No. 668142 (SPCCT). This study was funded by the British Heart Foundation (RG/20/1/34802), the BHF Centre of Excellence (RE/08/03), and the Chilean Agency of Technology and Science (CONICYT-PIA-Anillo ACT1416). This work was also supported by the Wellcome EPSRC Centre for Medical Engineering at King's College London (WT 203148/ $\mathrm{Z} / 16 / \mathrm{Z}$ ) and the Department of Health through the National Institute for Health Research (NIHR) comprehensive Biomedical Research Centre award to Guy's \& St Thomas' NHS Foundation Trust in partnership with King's College London and King's College Hospital NHS Foundation Trust.

\section{ABBREVIATIONS}

CNR, contrast-to-noise ratio; DIPEA, N,N-diisopropylethylamine; DOTA, 1,4,7,10-tetraazacyclododecane-1,4,7,10-tetraacetic acid; HBTU, $N, N, N^{\prime}, N^{\prime}$-tetramethyl-O- $(1 H$-benzotriazol-1-yl)uronium hexafluorophosphate; HEPES, N-(2hydroxyethyl)piperazine- $N^{\prime}$-(2-ethanesulfonic acid); IQR, interquartile range; LGE, late gadolinium enhancement; NMRD, nuclear magnetic resonance dispersion; PyBOP, benzotriazol1-yloxytripyrrolidinophosphonium hexafluorophosphate; SPPS, solid phase peptide synthesis; SPR, surface plasmon resonance; TE, tropoelastin

\section{REFERENCES}

(1) Tarkin, J. M.; Dweck, M. R.; Evans, N. R.; Takx, R. A. P.; Brown, A. J.; Tawakol, A.; Fayad, Z. A.; Rudd, J. H. F. Imaging atherosclerosis. Circ. Res. 2016, 118, 750-769.

(2) Virmani, R.; Burke, A. P.; Farb, A.; Kolodgie, F. D. Pathology of the vulnerable plaque. J. Am. Coll. Cardiol. 2006, 47, C13-C18.

(3) Virmani, R.; Kolodgie, F. D.; Burke, A. P.; Finn, A. V.; Gold, H. K.; Tulenko, T. N.; Wrenn, S. P.; Narula, J. Atherosclerotic plaque progression and vulnerability to rupture: angiogenesis as a source of intraplaque hemorrhage. Arterioscler., Thromb., Vasc. Biol. 2005, 25, 2054-2061.

(4) Duivenvoorden, R.; Mulder, W. J. M. Imaging tropoelastin in atherosclerosis. Circ. Cardiovasc. Imaging 2018, 11, No. e008147. 
(5) Krettek, A.; Sukhova, G. K.; Libby, P. Elastogenesis in human arterial disease: a role for macrophages in disordered elastin synthesis. Arterioscler., Thromb., Vasc. Biol. 2003, 23, 582-587.

(6) Rodríguez, C.; Alcudia, J. F.; Martínez-González, J.; Raposo, B.; Navarro, M. A.; Badimon, L. Lysyl oxidase (LOX) down-regulation by TNFalpha: a new mechanism underlying TNFalpha-induced endothelial dysfunction. Atherosclerosis 2008, 196, 558-564.

(7) Rodríguez, C.; Martínez-González, J.; Raposo, B.; Alcudia, J. F.; Guadall, A.; Badimon, L. Regulation of lysyl oxidase in vascular cells: lysyl oxidase as a new player in cardiovascular diseases. Cardiovasc. Res. 2008, 79, 7-13.

(8) Rodríguez, C.; Raposo, B.; Martínez-González, J.; Casaní, L.; Badimón, L. Low density lipoproteins downregulate lysyl oxidase in vascular endothelial cells and the arterial wall. Arterioscler., Thromb., Vasc. Biol. 2002, 22, 1409-1414.

(9) Phinikaridou, A.; Lacerda, S.; Lavin, B.; Andia, M. E.; Smith, A.; Saha, P.; Botnar, R. M. Tropoelastin a novel marker for plaque progression and instability. Circ. Cardiovasc. Imaging 2018, 11, No. e007303.

(10) Phinikaridou, A.; Andia, M. E.; Indermuehle, A.; Onthank, D. C.; Cesati, R. R.; Smith, A.; Robinson, S. P.; Saha, P.; Botnar, R. M. Vascular remodelling and plaque vulnerability in a rabbit model of atherosclerosis: comparison of delayed enhancement MR imaging with an elastin-specific contrast agent and unenhanced black-blood MR imaging. Radiology 2014, 271, 390-399.

(11) Indik, Z.; Yeh, H.; Ornstein-Goldstein, N.; Sheppard, P.; Anderson, N.; Rosenbloom, J. C.; Peltonen, L.; Rosenbloom, J. Alternative splicing of human elastin mRNA indicated by sequence analysis of cloned genomic and complementary DNA. Proc. Natl. Acad. Sci. U. S. A. 1987, 84, 5680-5684.

(12) Heinz, A.; Jung, M. C.; Jahreis, G.; Rusciani, A.; Duca, L.; Debelle, L.; Weiss, A. S.; Neubert, R. H. H.; Schmelzer, C. E. H. The action of neutrophil serine proteases on elastin and its precursor. Biochimie 2012, 94, 192-202.

(13) Rodríguez, C.; Alcudia, J. F.; Martínez-González, J.; Guadall, A.; Raposo, B.; Sánchez-Gómez, S.; Badimon, L. Statins normalize vascular lysyl oxidase down-regulation induced by proatherogenic risk factors. Cardiovasc. Res. 2009, 83, 595-603.

(14) Huffman, M. D.; Curci, J. A.; Moore, G.; Kerns, D. B.; Starcher, B. C.; Thompson, R. W. Functional importance of connective tissue repair during the development of experimental abdominal aortic aneurysms. Surgery 2000, 128, 429-438.

(15) Mäki, J. M.; Räsänen, J.; Tikkanen, H.; Sormunen, R.; Mäkikallio, K.; Kivirikko, K. I.; Soininen, R. Inactivation of the lysyl oxidase gene Lox leads to aortic aneurysms, cardiovascular dysfunction, and perinatal death in mice. Circulation 2002, 106, 2503-2509.

(16) Li, D. Y.; Brooke, B.; Davis, E. C.; Mecham, R. P.; Sorensen, L. K.; Boak, B. B.; Eichwald, E.; Keating, M. T. Elastin is an essential determinant of arterial morphogenesis. Nature 1998, 393, 276-280.

(17) van Herck, J. L.; de Meyer, G. R. Y.; Martinet, W.; van Hove, C. E.; Foubert, K.; Theunis, M. H.; Apers, S.; Bult, H.; Vrints, C. J.; Herman, A. G. Impaired fibrillin-1 function promotes features of plaque instability in apolipoprotein E-deficient mice. Circulation 2009 $120,2478-2487$.

(18) van der Donckt, C.; van Herck, J. L.; Schrijvers, D. M.; Vanhoutte, G.; Verhoye, M.; Blockx, I.; van der Linden, A.; Bauters, D.; Lijnen, H. R.; Sluimer, J. C.; Roth, L.; van Hove, C. E.; Fransen, P.; Knaapen, M. W.; Hervent, A. S.; de Keulenaer, G. W.; Bult, H.; Martinet, W.; Herman, A. G.; de Meyer, G. R. Y. Elastin fragmentation in atherosclerotic mice leads to intraplaque neovascularization, plaque rupture, myocardial infarction, stroke, and sudden death. Eur. Heart J. 2015, 36, 1049-1058.

(19) Belknap, J. K.; Grieshaber, N. A.; Schwartz, P. E.; Orton, E. C.; Reidy, M. A.; Majack, R. A. Tropoelastin gene expression in individual vascular smooth muscle cells. Relationship to DNA synthesis during vascular development and after arterial injury. Circ. Res. 1996, 78, 388-394.
(20) Makowski, M. R.; Wiethoff, A. J.; Blume, U.; Cuello, F.; Warley, A.; Jansen, C. H. P.; Nagel, E.; Razavi, R.; Onthank, D. C.; Cesati, R. R.; Marber, M. S.; Schaeffter, T.; Smith, A.; Robinson, S. P.; Botnar, R. M. Assessment of atherosclerotic plaque burden with an elastinspecific magnetic resonance contrast agent. Nat. Med. 2011, 17, 383388 .

(21) Makowski, M. R.; Preissel, A.; von Bary, C.; Warley, A.; Schachoff, S.; Keithan, A.; Cesati, R. R.; Onthank, D. C.; Schwaiger, M.; Robinson, S. P.; Botnar, R. M. Three-dimensional imaging of the aortic vessel wall using an elastin-specific magnetic resonance contrast agent. Invest. Radiol. 2012, 47, 438-444.

(22) Botnar, R. M.; Wiethoff, A. J.; Ebersberger, U.; Lacerda, S.; Blume, U.; Warley, A.; Jansen, C. H.; Onthank, D. C.; Cesati, R. R.; Razavi, R.; Marber, M. S.; Hamm, B.; Schaeffter, T.; Robinson, S. P.; Makowski, M. R. In vivo assessment of aortic aneurysm wall integrity using elastin-specifc molecular magnetic resonance imaging. Circ. Cardiovasc. Imaging 2014, 7, 679-689.

(23) von Bary, C.; Makowski, M.; Preissel, A.; Keithahn, A.; Warley, A.; Spuentrup, E.; Buecker, A.; Lazewatsky, J.; Cesati, R. R.; Onthank, D.; Schickl, N.; Schachoff, S.; Hausleiter, J.; Schömig, A.; Schwaiger, M.; Robinson, S.; Botnar, R. MRI of coronary wall remodeling in a swine model of coronary injury using an elastin-binding contrast agent. Circ. Cardiovasc. Imaging 2011, 4, 147-155.

(24) Wildgruber, M.; Bielicki, I.; Aichler, M.; Kosanke, K.; Feuchtinger, A.; Settles, M.; Onthank, D. C.; Cesati, R. R.; Robinson, S. P.; Huber, A. M.; Rummeny, E. J.; Walch, A. K.; Botnar, R. M. Assessment of myocardial infarction and postinfarction scar remodeling with an elastin-specifc magnetic resonance agent. Circ. Cardiovasc. Imaging 2014, 7, 321-329.

(25) Protti, A.; Lavin, B.; Dong, X.; Lorrio, S.; Robinson, S.; Onthank, D.; Shah, A. M.; Botnar, R. M. Assessment of myocardial remodeling using an elastin/tropoelastin specifc agent with high feld magnetic resonance imaging (MRI). J. Am. Heart Assoc. 2015, 4, No. e001851.

(26) Onthank, D.; Yalamanchili, P.; Cesati, R.; Lazewatsky, J.; Azure, M.; Hayes, M.; Kavosi, M.; Spencer, K.; Sousa, D.; Wexler, E.; Lamoy, M.; Harris, T.; Hu, C.; Jones, R.; Dwyer, G.; Casebier, D.; Robinson, S. Abstract 1914: BMS753951: a novel low molecular weight magnetic resonance contrast agent selective for arterial wall imaging. Circulation 2007, 116, II 411-II412.

(27) Lavin, B.; Lacerda, S.; Andia, M. E.; Lorrio, S.; Bakewell, R.; Smith, A.; Rashid, I.; Botnar, R. M.; Phinikaridou, A. Tropoelastin: an in vivo imaging marker of dysfunctional matrix turnover during abdominal aortic dilation. Cardiovasc. Res. 2020, 116, 995-1005.

(28) Wu, X.; Burden-Gulley, S. M.; Yu, G.-P.; Tan, M.; Lindner, D.; Brady-Kalnay, S. M.; Lu, Z.-R. Synthesis and evaluation of a peptide targeted small molecular Gd-DOTA monoamide conjugate for MR molecular imaging of prostate cancer. Bioconjugate Chem. 2012, 23, $1548-1556$

(29) Tripepi, M.; Capuana, F.; Gianolio, E.; Kock, F. V. C.; Pagoto, A.; Stefania, R.; Digilio, G.; Aime, S. Synthesis of high relaxivity gadolinium AAZTA tetramers as building blocks for bioconjugation. Bioconjugate Chem. 2018, 29, 1428-1437.

(30) Schirra, C. O.; Brendel, B.; Anastasio, M. A.; Roessl, E. Spectral CT: a technology primer for contrast agent development. Contrast Media Mol. Imaging 2014, 9, 62-70.

(31) Si-Mohamed, S.; Bar-Ness, D.; Sigovan, M.; Cormode, D. P.; Coulon, P.; Coche, E.; Vlassenbroek, A.; Normand, G.; Boussel, L.; Douek, P. Review of an initial experience with an experimental spectral photon-counting computed tomography system. Nucl. Instrum. Methods Phys. Res., Sect. A 2017, 873, 27-35.

(32) Schlomka, J.; Roessl, E.; Dorscheid, R.; Dill, S.; Martens, G.; Istel, T.; Livne, A. Experimental feasibility of multi-energy photoncounting K-edge imaging in pre-clinical computed tomography. Phys. Med. Biol. 2008, 53, 4031-4047.

(33) Crich, G.; Cabella, C.; Barge, A.; Belfiore, S.; Ghirelli, C.; Lattuada, L.; Lanzardo, S.; Mortillaro, A.; Tei, L.; Visigalli, M.; Forni, G.; Aime, S. In vitro and in vivo magnetic resonance detection of 
tumor cells by targeting glutamine transporters with Gd-based probes. J. Med. Chem. 2006, 49, 4926-4936.

(34) Dubey, L. V.; Dubey, I. Y. Side reactions of onium coupling reagents $\mathrm{BOP}$ and $\mathrm{HBTU}$ in the synthesis of silica polymer supports. Ukr. Bioorg. Acta 2005, 1, 13-19.

(35) Gringeri, C. V.; Menchise, V.; Rizzitelli, S.; Cittadino, E.; Catanzaro, V.; Dati, G.; Chaabane, L.; Digilio, G.; Aime, S. Novel Gd(III)-based probes for MR molecular imaging of matrix metalloproteinases. Contrast Media Mol. Imaging 2012, 7, 175-184.

(36) Tei, L.; Gugliotta, G.; Baranyai, Z.; Botta, M. A new bifunctional $\mathrm{Gd}^{\mathrm{III}}$ complex of enhanced efficacy for MR-molecular imaging applications. Dalton Trans. 2009, 9712-9714.

(37) Aime, S.; Botta, M.; Terreno, E. Gd(III)-based contrast agents for MRI. Adv. Inorg. Chem. 2005, 57, 173-237.

(38) Aime, S.; Botta, M.; Esteban-Gómez, D.; Platas-Iglesias, C. Characterisation of magnetic resonance imaging (MRI) contrast agents using NMR relaxometry. Mol. Phys. 2019, 117, 898-909.

(39) Caravan, P.; Ellison, J. J.; McMurry, T. J.; Lauffer, R. B. Gadolinium(III) chelates as MRI contrast agents: structure, dynamics, and applications. Chem. Rev. 1999, 99, 2293-2352.

(40) Tei, L.; Barge, A.; Geninatti-Crich, S.; Pagliarin, R.; Negri, V.; Ramella, D.; Cravotto, G.; Aime, S. Target visualization by MRI using the avidin/biotin amplification route: synthesis and testing of a biotin-Gd-DOTA monoamide trimer. Chem. - Eur. J. 2010, 16, 8080-8087.

(41) Catanzaro, V.; Gringeri, C. V.; Menchise, V.; Padovan, S.; Boffa, C.; Dastrù, W.; Chaabane, L.; Digilio, G.; Aime, S. A $R_{2 p} / R_{1 p}$ Ratiometric procedure to assess matrix metalloproteinase-2 activity by magnetic resonance imaging. Angew. Chem., Int. Ed. 2013, 52, 39263930.

(42) Pagoto, A.; Stefania, R.; Garello, F.; Arena, F.; Digilio, G.; Aime, S.; Terreno, E. Paramagnetic phospholipid-based micelles targeting VCAM-1 receptors for MRI visualization of inflammation. Bioconjugate Chem. 2016, 27, 1921-1930.

(43) Szijj, P. A.; Bahou, C.; Chudasama, V. Minireview: Addressing the retro-Michael instability of maleimide bioconjugates. Drug Discovery Today Technol. 2018, 30, 27-34.

(44) Tei, L.; Baranyai, Z.; Gaino, L.; Forgács, A.; Vágner, A.; Botta, $\mathrm{M}$. Thermodynamic stability, kinetic inertness and relaxometric properties of monoamide derivatives of lanthanide(III) DOTA complexes. Dalton Trans. 2015, 44, 5467-5478.

(45) Di Gregorio, E.; Gianolio, E.; Stefania, R.; Barutello, G.; Digilio, G.; Aime, S. On the fate of MRI Gd-based contrast agents in cells. Evidence for extensive degradation of linear complexes upon endosomal internalization. Anal. Chem. 2013, 85, 5627-5631.

(46) Barge, A.; Cravotto, G.; Gianolio, E.; Fedeli, F. How to determine free $\mathrm{Gd}$ and free ligand in solution of Gd chelates. A technical note. Contrast Media Mol. Imaging 2006, 1, 184-188.

(47) De Rosa, L.; Capasso, D.; Diana, D.; Stefania, R.; Di Stasi, R.; Fattorusso, R.; D'Andrea, L. D. Metabolic and conformational stabilization of a VEGF-mimetic beta-hairpin peptide by clickchemistry. Eur. J. Med. Chem. 2021, 222, 113575.

(48) Heinrich, L.; Tissot, N.; Hartmann, D. J.; Cohen, R. Comparison of the results obtained by ELISA and surface plasmon resonance for the determination of antibody affinity. J. Immunol. Methods 2010, 352, 13-22. 